\title{
Trends in Arctic seasonal and extreme precipitation in recent decades
}

Lejiang Yu ( $\nabla$ yulejiang@sina.com.cn )

Polar Research Institute of China

\section{Shiyuan Zhong}

Michigan State University

\section{Research Article}

Keywords: Arctic extreme precipitation, the Arctic Oscillation (AO), the Arctic Dipole (AD), Self-Organized Map (SOM)

Posted Date: April 13th, 2021

DOI: https://doi.org/10.21203/rs.3.rs-385100/v1

License: (1) This work is licensed under a Creative Commons Attribution 4.0 International License. Read Full License

Version of Record: A version of this preprint was published at Theoretical and Applied Climatology on July 13th, 2021. See the published version at https://doi.org/10.1007/s00704-021-03717-7. 
Trends in Arctic seasonal and extreme precipitation in recent decades

\author{
Lejiang Yu \\ MNR Key Laboratory for Polar Science, Polar Research Institute of China, Shanghai, \\ China, 200136 \\ Southern Marine Science and Engineering Guangdong Laboratory, Zhuhai, China
}

Shiyuan Zhong

Department of Geography, Environment and Spatial Sciences, Michigan State

University, East Lansing, MI, USA

Corresponding Author's address Dr. Lejiang Yu

MNR Key Laboratory for Polar Science, Polar Research Institute of China, Shanghai,

China

Jinqiao Road 451, 200136, Shanghai, China

Phone: 0086-020-58712034, email: yulejiang@sina.com.cn 


\section{Abstract}

Daily precipitation data from the European Centre for Medium-Range Weather Forecasts (ERA-Interim) from 1979 to 2016 are analyzed to determine the trends in seasonal and extreme precipitation across the pan-Arctic and estimate the contributions to the trends from the dynamic (e.g. changes in circulation patterns) and thermodynamic processes (e.g., sea ice melt - water vapor feedback) and their interactions. The trends in the seasonal total precipitation are generally consistent with the trends in the occurrence of seasonal extreme precipitation. Although the trends vary considerably in direction and magnitude across the pan-Arctic and the seasons, more regions experience a statistically significant positive trend than negative trend, particularly in autumn and winter seasons and over areas of the Arctic Ocean and the northern North Atlantic. Statistically significant negative trends are mostly found in areas of northern Eurasian and North America. The thermodynamic processes account for more than $85 \%$ of the total trends, with the rest of the trends explained by the dynamic processes (e.g., changes in circulation patterns) and the interaction between dynamic and thermodynamic processes.

Keywords Arctic extreme precipitation; the Arctic Oscillation (AO); the Arctic Dipole (AD); Self-Organized Map (SOM) 


\section{Introduction}

Precipitation is a crucial component of the Arctic freshwater budget that influences, among other things, North Atlantic deep-water formation and global thermohaline circulation (Walsh et al. 1998). Precipitation can modulate the formation and maintenance of sea ice by changing stratification of the Arctic Ocean (Barry and Serreze 2000). Snow on sea ice, because of its high surface albedo, thermal emissivity and thermal insulating properties, also can affect the sea ice - albedo feedback process (Screen and Simmonds, 2012) and the seasonal variability of sea ice (Henderson et al., 2018). Snow over ice sheets can modulate ice sheet mass balance and sea level change (Rignot and Thomas 2002). In the past several decades, the Arctic has experienced significant warming and sea ice loss (Stroeve et al. 2012). The increase in local evaporation associated with sea ice loss in the past two decades has contributed to an increase in Arctic sourced moisture at a rate of $18.2 \pm 4.6 \%$ and $10.8 \pm 3.6 \%$ per $100,000 \mathrm{~km}^{2}$ sea ice loss in the Canadian Arctic and Greenland Sea regions, respectively (Kopec et al. 2016), and more moisture in the atmosphere has contributed to enhanced precipitation and to amplification of water vapor-cloud-radiation feedback that has in term reinforced Arctic warming (Cai 2005). Despite the essential role precipitation plays in the Arctic environment, questions remain regarding the spatiotemporal variability of precipitation and the driving forces behind it, due mostly to the relatively large uncertainties in observational data (Behrangi et al. 2012), large biases in model simulations at high latitudes (Stephens et al. 2010) and the large differences in precipitation magnitudes between various reanalyses datasets in the 
Arctic (Boisvert et al. 2018; Barrett et al. 2020).

A number of studies have examined precipitation in the Arctic region. Observations from gauge network (Legates and Willmott 1990; Yang 1999), gridded reanalysis products (Serreze and Hurst 2000; Vihma et al. 2016; Boisvert et al. 2018; Barrett et al. 2020) and satellite images (Groves and Francis 2002) have portrayed a highly heterogeneous annual precipitation pattern over the Arctic, varying between minima over the Canadian Archipelago and the Beaufort Sea and maxima in the North Atlantic Ocean. Precipitation in the Arctic also displays a strong seasonality that varies with region, with winter maximum and summer minimum in the northern Atlantic and the opposite in the Arctic land and the central Arctic Ocean (Serreze et al. 2005; Vihma et al. 2016). There have been trends in the Arctic precipitation, with direction and magnitude highly variable depending on time periods, regions and seasons (Vihma et al. 2016; McAfee et al. 2013; 2014). Over most of the Arctic land, both observations (Hanssen-Bauer and Førland 1998; Berner et al. 2005; Khon et al. 2007) and climate model simulations (Kattsov and Walsh 2000; Kattsov et al. 2007) revealed an increasing trend in precipitation, particularly in winter season, in the later part of the $20^{\text {th }}$ century, but an opposite trend was found for the annual snow amount and total number of snow days for the 1979-2009 period (Liston and Hiemstra 2011). These trends have been attributed to anthropogenic influences (Min et al. 2008) and an increase in local moisture source from evaporations of ice-free ocean surfaces as well as moisture transport by atmospheric circulations (Ghatak et al. 2012; Park et al. 2013; Kopec et al. 2016). Other factors have also been evoked to explain the 
increasing precipitation trend in parts of the Arctic. For example, the Arctic Amplification and the increase in the Greenland Blocking Index have been linked to the increasing mean annual precipitation in southeast Greenland in the 1958-2013 period (Auger et al. 2017), and the decadal modulation of the El Niño-Southern Oscillation (ENSO) has been used to partially explain a decadal-scale variability of October-March Arctic precipitation for the 1990-2001 period (Hegyi and Deng 2011). However, using precipitation data from several reanalysis products that correlate well despite large magnitude differences, Boisvert et al. (2018) and Barrentt et al. (2020) did not find an increasing trend in precipitation over the Arctic Ocean for the periods of 2000-2016 and 1980-2017, respectively.

Several studies have also investigated extreme precipitation, its variability and the underlying atmospheric conditions in various regions of Arctic including Alaska (Kane et al. 2003; Glisan et al. 2016, Glisan and Gutowski Jr 2014a; 2014b), Canada (Glisan and Gutowski Jr 2014a; 2014b) and Svalbard Archipelago (Serreze et al. 2015). These studies underscore the importance of low-level moisture advection and its interaction with topography in the occurrence of extreme precipitation events in regions of the Arctic.

Annual precipitation over the Arctic is projected to increase under increasing greenhouse gas emissions scenarios (Cassano et al. 2007; Holland et al. 2007; Vavrus et al. 2012; Bintanja and Selten 2014; Singh et al. 2017). The increasing Arctic precipitation has been linked mainly to strengthening moisture transport into the Arctic (Held and Soden 2006; Higgins and Cassano 2009; Skific et al. 2009a; 2009b; 
Hwang and Frierson 2010; Bengtsson et al. 2011; Zhang et al. 2013), intensification of local surface evaporation (Bintanja and Selten 2014) and a combination of both factors (Singh et al. 2017). The magnitude of increasing Arctic precipitation is constrained by the balance between dry static energy and latent heating (Vihma et al. 2016; Anderson et al. 2018). Extreme precipitation in the Arctic is expected to increase under global warming (Meehl et al. 2005; Khon et al. 2007). Particularly, a mid-century increase in the frequency and intensity of extreme precipitation, especially in the winter season, is projected for East Siberia, the Barents Sea (Saha et al. 2006) and the Norwegian west coast (Heikkilä and Sorteberg 2012).

Mean and extreme precipitation has been changing over both Arctic land and ocean and the nature and magnitudes of the changes are region- and season-dependent (McAfee et al. 2014). Although previous studies have linked several atmospheric and oceanic processes to the changing Arctic precipitation, more investigations are necessary to help identify the drivers for and estimate their relative contributions to the changes in Arctic precipitation. . In this study, we first analyze daily precipitation data from a global reanalysis for a 38-year (1979-2016) period to further characterize the spatial patterns of Arctic seasonal total and extreme precipitation and their trends. We then apply the Self-Organizing Map (SOM) method (Kohonen 2001) to explain the trends by means of dynamic and thermodynamic contributions and the contribution from their interactions.

\section{Dataset and methods}

The domain of the study is the region north of $60^{\circ} \mathrm{N}$, or the pan-Arctic, and across 
the region there has been significant warming in recent decades. The study utilizes daily precipitation and $500 \mathrm{hPa}$ geopotential height data from the European Centre for Medium-Range Weather Forecasts (ECMWF) Interim reanalysis (ERA-Interim, Dee et al. 2011). ERA-Interim precipitation data have shown reasonable agreement with the observed magnitudes and temporal variations of precipitation over the Arctic Ocean (Boisvert et al. 2018), its surrounding continents (Lindsay et al. 2014; Lader et al. 2016), and the whole pan-Arctic region (Behrangi et al. 2016). Both data are on a latitude and longitude grid with half-degree grid spacing for the daily precipitation data and one-degree for the $500 \mathrm{hPa}$ geopotential height data. In addition to daily precipitation, we also examine extreme precipitation defined as when the daily amount exceeds $\eta$ percentile of all daily precipitation data in the 1979-2016 period, where $\eta$ is chosen to be 90 and 95 . Since the results for extreme precipitation are quite similar between $\eta=90$ or $\eta=95$, we will only present the results for extreme precipitation defined using $\eta=95$.

We employ the SOM method to cluster the atmospheric circulation patterns represented by the $500-\mathrm{hPa}$ geopotential height anomalies. SOM utilizes a neural network algorithm with unsupervised learning to transform a multi-dimensional dataset into a lower, usually two-dimensional array (Kohonen 2001). Each node in the array has a vector that displays a spatial pattern of the multi-dimensional data. A Sammon map (Sammon 1969) is applied to represent local relationships between the nodes in the array. The distance between the nodes indicates the similarity between the spatial patterns of the nodes. An advantage of SOM compared to the more 
traditional dimension-reduction methods, such as Empirical Orthogonal Function (EOF), is that SOM does not require orthogonality of any two nodes (Reusch et al. 2005). The SOM technique has been utilized in a number of previous studies on Arctic precipitation and atmospheric moisture transport into the Arctic (Cassano et al. 2007; Schuenemann et al. 2009; Skific et al. 2009a; 2009b; Heikkilä and Sorteberg 2012; Glisan et al. 2016; Mioduszewski et al. 2016). Here, we apply the SOM method to identify the spatial patterns of daily $500-\mathrm{hPa}$ geopotential height anomalies relative to the climatological height values in the region north of $60^{\circ} \mathrm{N}$ for each season. Before SOM analyses we need to determine the number of SOM nodes. The rule for choosing the number of SOM nodes is that the number both captures the representative spatial patterns and avoids overly similar patterns with the difference of unnecessary details between the patterns (Lee and Feldstein 2013; Gibson et al. 2017). To determine the number, we computed spatial correlations between the daily $500-\mathrm{hPa}$ geopotential height anomalies and the best matching SOM pattern. The averaged spatial correlations for all daily data across all SOM nodes at different grids are shown in Table 1 . The averaged correlation gradually increases from 0.29 for grid $3 \times$ 1 to 0.46 for grid $3 \times 3$, dropping back to 0.43 for grid $5 \times 2$ before becoming steady with only slight variations among grids $4 \times 3,5 \times 3$ and $4 \times 4$. Thus a $4 \times 3$ SOM grid seems to satisfy the aforementioned rule and is utilized for the analysis.

To assess the driving force behind the trends in the seasonal and extreme precipitation data, we adopt the method of Cassano et al. (2007) and calculate the dynamic and thermodynamic contributions to the trends using the following 
equations:

$$
\begin{aligned}
& E=\sum_{i=1}^{K} E_{i} f_{i}=\sum_{i=1}^{K}\left(\bar{E}_{i}+E_{i}^{\prime}\right)\left(\bar{f}_{i}+f_{i}^{\prime}\right) \\
& \frac{d E}{d t}=\sum_{i=1}^{K}\left(\bar{f}_{i} \frac{d E_{i}^{\prime}}{d t}+\bar{E}_{i} \frac{d f_{i}^{\prime}}{d t}+\frac{d\left(E_{i}^{\prime} f_{i}^{\prime}\right)}{d t}\right)
\end{aligned}
$$

where $f_{i}$ is the frequency of occurrences of the SOM node $i, E_{i}$ is Arctic precipitation corresponding to the SOM node $i$ and $K$ is the total number of SOM nodes $(K=12)$. $\bar{E}_{i}, \bar{f}_{i}$ and $E_{i}^{\prime}, f_{i}^{\prime}$ represent the 38-year average and deviation from the average (also known as anomaly), respectively. Equation (1) indicates that the total seasonal (or extreme) Arctic precipitation $(E)$ is the summation of the product of the seasonal (or extreme) precipitation corresponding to each SOM node and the frequency of occurrence of the SOM node over all 12 nodes. Note here each SOM node represents an atmospheric circulation pattern characterized by the $500-\mathrm{hPa}$ geopotential height anomalies. Equation (2) indicates that the total trend in the seasonal (or extreme) Arctic precipitation (left-hand side) can be divided into three components (right-hand side): the thermodynamic component (first term), dynamic component (second term) and their interaction (third term) summed over all SOM nodes. The thermodynamic component for each SOM node is calculated by the product of the frequencies of occurrence of the SOM node $i$ averaged over the 38 years $\left(\bar{f}_{i}\right)$ and the trend in Arctic precipitation anomalies related to this SOM node $\left(\frac{d E_{i}{ }^{\prime}}{d t}\right)$. A physical explanation of the thermodynamic contribution is the changes in precipitation when large-scale circulation pattern (represented here by the $500-\mathrm{hPa}$ geopotential height field) remain unchanged. An example may be changes in precipitation resulting from changes in 
local surface heating and evapotranspiration. The dynamic component for each SOM node is obtained by the product of the average Arctic precipitation per SOM node $i$ occurrence $\left(\bar{E}_{i}\right)$ and the trend in the anomalous frequency of occurrence of SOM node $i\left(\frac{d f_{i}^{\prime}}{d t}\right)$. The dynamic contribution can be understood as changes in the frequency of occurrence of atmospheric circulation patterns while holding precipitation pattern steady. An example is changes in the frequency, position and intensity of precipitation-producing low pressure systems. In nature, the thermodynamic and dynamic components cannot be completely separated. For example, atmospheric circulations are modified by pressure gradient resulting from thermodynamic energy exchange between the earth and the atmosphere, while atmospheric circulations provide the background environment in which thermodynamic processes take place. The interaction between dynamic and thermodynamic components are defined here by the trend $\left(\frac{d}{d t}\right)$ in the product of the anomalous frequency of occurrence of SOM node $i\left(f_{i}^{\prime}\right)$ and the Arctic precipitation anomaly per SOM node occurrence $\left(E_{i}^{\prime}\right)$. An example of the interaction is changes in the occurrences of atmospheric circulation patterns induced by Arctic amplification.

\section{Results}

\subsection{Climatology and trends of seasonal precipitation}

Seasonal total precipitation averaged over the 38 years (Figure 1) varies spatially across the Arctic and the spatial patterns appear to be similar for most of the year except for summer. In general, higher precipitation tends to occur over northern 
Atlantic Ocean, the western coasts of northern Europe, and a small area in southern Alaska where snow/ice cover is low. This spatial distribution of precipitation is in line with the pattern of climatological moisture convergence (Skific et al. 2009b). In summer, larger precipitation shifts to regions inland, particularly in Alaska and eastern Siberia, where strong baroclinicity related to larger land-ocean temperature contrasts helps facilitate cyclogenesis producing more precipitation. The steep coastal orography also helps enhance precipitation (Serreze and Barry 2005). These results are similar to Vihma et al. (2016).

Nearly identical spatial patterns are also observed for extreme precipitation (not shown), as reflected by high spatial correlation coefficients of $0.95,0.96$ and 0.97 for spring, autumn and winter and 0.87 for summer between the extreme precipitation and the total precipitation. The portion of the total precipitation accounted for by extreme events varies across the pan-Arctic (Figure 2), where larger ratios occur over northern Canada due to strong baroclinicity between land and ocean, and the northeastern coast of Greenland due to interactions between cyclones and topography (Schuenemann et al. 2009; Hakuba et al. 2012).

The exact percentages between the extreme precipitation and the total precipitation depend on season. High percentages are found in northeastern Greenland, with ratios ranging from $65.6 \%$ in winter to $73.7 \%$ in summer. High ratios exceeding $50 \%$ also occur over northwestern Eurasia. These high ratios suggest that precipitation in these regions is dominated by extreme events. Smaller fraction of extreme precipitation is found in northern Atlantic Ocean and the Barents Sea during 
non-summer seasons $(20.4 \%$ in winter) and over Alaska in summer (19.8\%). The spatial distribution of the ratios of the extreme precipitation to the total precipitation (Figure 2) appears to be inversely correlated to the spatial pattern of the total precipitation (Figure 1), especially in winter when the spatial correlation coefficient is -0.57. The negative correlation indicates that areas with more precipitation tend to have a more even distribution of daily precipitation in a season.

The trends in the Arctic seasonal precipitation also display considerable spatial variability (Figure 3). In spring and summer, negative trends mainly occur over Alaska, eastern Siberia, Greenland and a small patch of northern Atlantic Ocean. These negative trends appear to retreat in autumn and winter to the southern parts of Northern Europe and the Bering Sea and the southern parts of the Barents Sea and Siberia. Autumn has the most extensive distribution of positive trends, encompassing most of the Arctic Ocean and northern Canada as well as eastern Siberia. In winter, positive trends occur over the Atlantic sector of the Arctic Ocean, Northern Europe, and some islands of northern Canada. Northern Europe also has positive trend in spring and summer, in addition to positive trends in the ocean north of Novaya Zemlya for spring and western Siberia for summer. Similar spatial patterns are found for the extreme precipitation (not shown), with spatial correlation coefficients between trends in extreme precipitation and in the total precipitation ranging from 0.77 in winter to 0.88 in summer.

The spatial patterns of the trends in the ratios of the extreme precipitation to the total precipitation (Figure 4) are somewhat similar to the patterns of the trends in the 
total seasonal precipitation in Figure 3, with spatial correlation coefficients ranging from 0.31 in winter to 0.50 in summer. The trends in the ratio also positively correlated with the trends in the extreme precipitation days (Figure 5), indicating that an increase (decrease) in the contribution of extreme precipitation to the total precipitation is largely due to an increase (decrease) in the number of extreme events, as compared to an increase in the intensity. Overall, the number of extreme precipitation days has been on a significant increasing trend across the Arctic Ocean during non-summer seasons, particularly in autumn. The potential drivers for this trend and the trend in the total seasonal precipitation are the focus of the next section.

\subsection{Physical drivers for the trends}

Following Cassano et al. (2007), the SOM method is utilized to investigate the potential drivers for trends in seasonal and extreme Arctic precipitation. Specifically, a $4 \times 3 \mathrm{SOM}$ grid is first applied to the $500-\mathrm{hPa}$ geopotential height anomalies to identify the main variability modes of atmospheric circulation for each season (Figures 6-9). The spatial patterns depicted by the 12 SOM nodes resemble Arctic Oscillation (AO) (Wallace and Gutzler 1981; Barnston and Livezey 1987) and Arctic Dipole (AD) (Wang et al. 2009) modes and their transition states. Specifically, nodes 5 and 8 have mirror-imaging spatial patterns that are similar to the negative- and positive-phase $\mathrm{AO}$ index, respectively. In contrast to nodes 5 and 8 showing anomalous high or low geopotential heights centered over the Arctic, nodes 4 and 9 for autumn and nodes 1 and 12 for other seasons have the anomalous high or low 
centered over the eastern Arctic Ocean. Nodes 3 and 10 have a spatial pattern similar to the positive- and negative-phases $\mathrm{AD}$ index, respectively. Patterns depicted by other nodes reflect a transition state between the $\mathrm{AO}$ and $\mathrm{AD}$ indices. For example, nodes 1 and 12 for autumn and nodes 4 and 9 for other seasons show an asymmetrical AD feature with large magnitude of height anomalies over western Arctic.

Each SOM node best represents the pattern of the 500-hPa height anomalies on some of the days during the study period and the percentage varies among the nodes, with higher percentages $(>10 \%)$ for nodes $1,4,9$, and 12 , and lower percentages $(<$ 5\%) for nodes 6 and 7 (Table 2). The most frequent pattern in autumn is node 1, depicting an asymmetrical AD structure where positive height anomalies prevail over most the Arctic Ocean. The most frequent pattern in the other seasons is node 12, with a spatial pattern resembling positive phase AO. The percentages are positively correlated with the magnitudes of anomalies.

Except for autumn, the frequency of occurrence of some SOM nodes appears to have a linear trend over the 38-year study period, although not all trends are significant at the $95 \%$ confidence level (Table 3 ). The frequency of occurrence exhibits an increasing trend for node 9 for spring and node 10 for summer, and a decreasing trend for node 3 in summer, which together suggesting a tendency of enhanced anticyclonic circulation over most of the Arctic Ocean, especially over western Arctic. This tendency is in agreement with the result of Ding et al. (2017). In winter, there is a significant negative trend in the frequency of occurrence for node 4 and 8 , and a positive trend for node 1 (Table 3 ), which together suggests an overall 
positive trend in the 500-hPa geopotential height across the Arctic.

The typical pattern of the anomalous daily precipitation corresponding to each of the 12 SOM nodes can be obtained by compositing anomalous daily precipitation patterns over all the days when the 500 -hPa height anomaly patterns are best matched by the SOM node. Evidently, as shown for the spring season (Figure 10), the spatial distribution of the anomalous precipitation is consistent with the pattern of anomalous atmospheric circulation and the influence of circulation on precipitation. Take nodes 3 and 4 as an example, the strong negative (positive) height anomalies over western (eastern) Arctic (Figure 6) implies a transport of moist and warm air into the northern Atlantic and the central Arctic by anomalous southerly-southwesterly winds, enhancing precipitation in these regions (Figure 10), and an anomalous dry and cold air flow into the Eurasian continent, reducing precipitation there (Figure 10). Likewise, anomalous southeasterly winds on the southern side of the anomalous high enhance precipitation over eastern Greenland for node 1, and northern Atlantic Ocean and northern Europe for node 2. Similar explanations can be invoked to explain the patterns in nodes 9-12. For nodes 4 and 8, the anomalous low (high) across the Arctic Ocean usually corresponds to more (less) precipitation over the Arctic. The composite maps for the number of days of extreme precipitation have similar spatial patterns to those of daily precipitation composites (Not shown).

We also examine relationships between anomalous circulation and precipitation patterns for autumn and winter when the largest increases in precipitation occurs (Figure 3 and 4). For the two seasons, precipitation anomalies with larger magnitude 
occur over the Atlantic sector of the Arctic Ocean and its peripheral land (Figures 11 and 12). The variability is out-of-phase between the western Nordic Sea, eastern Greenland Island and the eastern Nordic Sea, western Norway for some nodes and seasons, such as Nodes 4, 8, 9, 10 in autumn and 1, 3, 4, 12 in winter, due possibly to the large cyclone and anticyclone over the eastern Arctic Ocean. The anomalous southeasterly (northwesterly) winds over the Nordic Sea produce more (less) precipitation over western Nordic Sea and eastern Greenland Island and less (more) precipitation over eastern Nordic Sea and western Norway. The mechanism for the uniform anomalies over the Nordic Sea is similar to that in spring.

As shown in Eq. (2), the total trend in the seasonal or extreme precipitation can be divided into thermodynamic and dynamic components and their interactions. But before assessing the relative contribution of each component to the total trend, it is useful to first examine the average trends in the precipitation patterns associated with the atmospheric circulation pattern depicted by each of the $12 \mathrm{SOM}$ nodes (Figure 13). The averaging is calculated over those grid points where trends are significant at $95 \%$ confidence level in Figures 3 and 5. Trends in both the seasonal total precipitation and in the number of days of extreme precipitation associated with different circulation patterns vary in sign and magnitudes. For both trends, summer season is dominated by negative values while the other seasons by positive values. For non-summer seasons, the largest negative trend is consistently with node 4 (Figure 13). The $500 \mathrm{hPa}$ height pattern in node 4 is an anomalous low (high) over the western (eastern) Arctic, which induces southerly anomalous winds that transport warm moist air from the south into 
the Arctic and produce more precipitation (Figure 6-9). However, a sharp decreasing trend in the frequency of occurrence of node 4 (Table 3) explains its large contribution to the negative trend in precipitation. Not surprisingly, a decomposition of node 4 trend indicates that the negative trend in node 4 is overwhelmingly dominated by the dynamic component at Tables 4-7, where dynamic component explains most of the negative trend.

More nodes have positive trends in the non-summer seasons and node 1 and 9 are further examined for their larger trends (Figure 13). Node 9, which is the largest in spring and the second largest in autumn, has comparable dynamic and thermodynamic components in spring (Table 4), but larger thermodynamic component in autumn (Table 6). Node 1, which dominates the positive trend in winter, has dynamic component exceeding thermodynamic component (Table 7). The significant positive trend in the occurrence of node 1 (Table 3 ) is favorable for more moist and warm air being transported into the central Arctic Ocean through the southerly anomalous winds induced by the anomalous high over the Arctic Ocean (Figure 9), leading to more precipitation occurrences there (Figure 10). The contribution from the interaction component is much smaller.

In contrast, summer-season trends vary considerably in sign and magnitude among the nodes (Figure 13). The largest positive trend is with node 9 and the largest negative is with node 3 (Table 5). For both nodes, the trends are dominated by the dynamic component (Table 5). The anomalous high in node 9 (Figure 7) advects cold and dry air from the central Arctic into Greenland, northern Atlantic Ocean and 
Alaska, decreasing summertime precipitation in these regions (Figure 13). The increasing occurrences of node 9 (Table 3 ) contribute to the negative trend in seasonal precipitation and occurrences of extreme precipitation in summer. The opposite occurs for node 3, for which the anomalous low corresponds to the positive precipitation anomalies and the decreasing occurrences of node 3 (Table 3 ) contribute to the negative precipitation trend (Table 5).

It is interesting to note that the dynamic component can be the dominant component for some nodes (e.g. nodes 4 and 9), but the contributions from dynamic components to the trends are positive for nearly half of the nodes and negative for the other half. When summed over all the nodes, the dynamic contribution to the total trend is therefore small compared to the thermodynamic components that are predominantly positive (Tables 3-6). As seen by the percentages of the grid-averaged total trends explained by the three components (Figure 14), the thermodynamic component dominates the total trends in the seasonal precipitation and in the number of days of extreme precipitation occurrences in all four seasons. The total percentages explained by the dynamic and interactive components are comparable and the sign of the trend varies with season.

There are considerable spatial variations in the contributions from the dynamic, thermodynamic and interaction components to the total trends in the seasonal precipitation (Figure 15) and the number of days of extreme precipitation events (Figures 116). The thermodynamic components are larger in magnitude, both positive and negative, across the domain. It is mostly positive over the Arctic Ocean except for 
summer when negative trends also occur in areas of Arctic Ocean. The reason for the negative trends in summer may be that the surface is not coupled to the atmosphere in summer like it is in other seasons (Deser et al., 2015). For dynamic components, large positive trends occur over eastern Greenland in autumn and winter and over the Kara and Laptev Seas in summer. The former is related to the negative phase of the AD and the latter is associated with the positive phase of the AO.

For the interaction component, which shows a larger spatial variation than that of the dynamic component, the negative trends over the central Arctic Ocean and positive trends over the Pacific sector of the Arctic in spring and winter tend to offset the effects of thermodynamic components. The negative trends over central Russia and northeastern Canada in autumn offset the positive trends related to the thermodynamic components. The opposite trends occur over North Europe and northeastern Canada in summer.

Recently, Arctic surface temperature has been increasing nearly twice as fast as the global average (Serreze and Barry 2011). This increase in surface air temperature allows for more local evaporation from ice-free ocean and land surfaces and therefore more water vapor amount in the atmosphere. An examination of the trend in the total column water vapor for each season (Figure 17) reveals a significant increasing trend that is, in general, consistent with that of seasonal precipitation (Figure 3). Our results agree with the study of Boisvert and Stroeve (2015) that showed a warmer and wetter Arctic in recent decades. There exist, however, some inconsistency in some regions, such as eastern Greenland in summer. The inconsistency may be related to water 
transport induced by water vapor gradient under certain atmospheric circulations. There are two mechanisms for the Arctic water vapor content changes: local increase in water vapor due to evaporations from warm ocean surfaces and poleward moisture transport from lower latitudes (Fearon et al., 2020). We calculated the trends in surface evaporation (Figure S1, Supplemental Materials). Positive trends occur only in summer over areas of the Arctic Ocean, which is consistent with the trends of water vapor content (Figure 17b). In autumn and winter, most of the Nordic Sea shows a positive trend, which explains a part of increasing water vapor content there. The increased evaporation over the Nordic Sea contributes not only to precipitation increase locally in the region, but also to remote precipitation increase over the central Arctic Ocean due to moisture transport by anomalous southerly winds. The inconsistence of spatial patterns between the trends in water vapor content and surface evaporation indicates the important role of moisture transport (Rinke et al., 2019). Cyclone activity explains most of moisture transport into the Arctic (Fearon et al., 2020). There is an increasing trend in frequency and intensity of cyclones in the Atlantic sector of the Arctic, which is related to more precipitation there (Stroeve et al., 2011). The increasing frequency of cyclones occurred over most of the central Arctic Ocean and toward the Pacific in winter and the region from the Laptev Sea toward Greenland and the Canadian archipelago in summer (Zahn et al., 2018). Cyclone activity index, which measures the intensity and the number and duration of cyclone activity, also shows a positive trend (Villamil-Otero et al., 2018). It appears that both the local surface evaporation associated with sea ice loss and the transport of 
moisture into the Arctic from lower latitudes related to cyclone activity may contribute to the changes of water vapor content and precipitation in the Arctic and that the latter has a larger contribution.

\section{Conclusions and discussions}

In this study, daily precipitation data from 1979 through 2016 are utilized to examine Arctic precipitation, focusing on the trends in the seasonal precipitation and the number of days of extreme precipitation defined as daily precipitation amount exceeding the $95^{\text {th }}$ percentile of the daily precipitation in a season over the study period. The forcing for the trends are examined by apportioning the trends to dynamic and thermodynamic components and their interactions, with dynamic component represented by changes in atmospheric circulation patterns identified using the SOM method and the 500-hPa geopoetntial height fields.

The contributions of extreme precipitation to the seasonal total precipitation vary across the Arctic, with larger contributions in northeastern Greenland and northeastern Canada and smaller contributions over Alaska in summer and the northern Atlantic Ocean and Barents Sea in other seasons. Trends are heterogeneous across the domain with season-dependent spatial patterns that are consistent between seasonal total and extreme precipitation. Trends over the Arctic Ocean are generally positive in autumn, transitioning to generally negative in summer. In winter and spring, positive (negative) trends occur mainly over the central Arctic Ocean (northern Eurasian continent) and the Atlantic sector of the Arctic (northern North America), respectively. 
The variability of daily Arctic atmospheric circulation patterns represented by the anomalous $500 \mathrm{hPa}$ geopotential heights north of $60^{\circ} \mathrm{N}$ and depicted by the $12 \mathrm{SOM}$ nodes is characterized mainly the $\mathrm{AD}$ and $\mathrm{AO}$ modes, and the trends of the variability are explained by an increase (decrease) in the frequency of occurrence of the negative (positive) phase of the $\mathrm{AD}$ and $\mathrm{AO}$. Together, it suggests that there is an increasing trend in geopotential heights across the Arctic, especially over the western Arctic.

During the non-summer seasons, most of the circulation patterns represented by the SOM nodes show a positive trend; the opposite occurs in summer. For the dominant nodes, the contributions to the trends in the seasonal total precipitation and the number of days of extreme precipitation are comparable from the thermodynamic and dynamic components, and they are larger than the interaction component. The dynamic contributions to the trends, which represent changes in the frequency of occurrence of circulation patterns, tend to be positive from nearly half of the nodes or patterns, but negative for the other half, and as a result, they collectively account for only a small portion of the total trends. The thermodynamic contributions, which are predominantly positive among the 12 nodes, explain for more than $85 \%$ of the total trends. The thermodynamic contributions can be linked to the increasing column water vapor in some regions, while in other regions the changes in total column water vapor gradient may play an import role. The contribution from the interaction component to the total trend is comparable to that of dynamic component.

Previous studies have also found positive trends in annual mean precipitation at northern high latitudes (Bengtsson et al. 2011; Trenberth 2011). These studies have 
suggested that the increasing annual mean precipitation results mainly from the positive trend in winter and that the change depends on periods of study, the regions of the study and the seasons (Min et al. 2008; Vihma et al. 2016). Our results suggest that averaging across the entire pan-Arctic, the increasing trend in seasonal (and extreme) precipitation is larger in autumn than winter, and that the average trend is negative in summer.

This study links the increasing Arctic precipitation to the thermodynamic contribution related to increasing column water vapor due to Arctic warming, which is consistent with the effect of the increasing anthropogenic forcing (Min et al. 2008; Bengtsson et al. 2011; Lique et al. 2016). The thermodynamic component also includes increasing poleward moisture transport due to changes of water vapor gradient (Zhang et al. 2013). Although the dynamic component explains less than $30 \%$ of the total trends over the study period, for certain nodes, dynamic contributions related to changes in the frequency of circulation patterns, are comparable to thermodynamic contributions. The change of the frequencies leads to anomalous positive height across the pan-Arctic, especially over the western pan-Arctic, which is in line with the strengthened Beaufort High (Wu et al. 2014). The interaction of thermodynamic and dynamic components represents the effect of anthropogenic forcing on the frequency of occurrences of atmospheric circulations such as AO (Zhang et al. 2013), though more about the interaction process needs to be understood (Vihma et al. 2016). 
Acknowledgements We thank the European Centre for Medium-Range Weather Forecasts (ECMWF) for the ERA-Interim data. This study is supported by the National Key R\&D Program of China (2019YFC1509103; 2017YFE0111700), and the National Natural Science Foundation of China (41922044). We also acknowledge the help from the two anonymous reviewers in improving the manuscript.

Competing Interests: The authors declare no competing financial interests.

Funding Statement: This study is supported by the National Key R\&D Program of China (2019YFC1509103; 2017YFE0111700), and the National Natural Science Foundation of China (41922044).

Author's Contribution: Lejiang Yu designed the research, analyzed the data, and wrote the first draft of the paper. Shiyuan Zhong revised the first draft and provided useful insights during various stages of the work.

Availability of data and material: Daily atmospheric variables are provided by the European Centre for Medium Range Weather Forecasts (ECMWF) Interim ReAnalysis (ERA-Interim) (https://www.ecmwf.int/en/forecasts/datasets/reanalysis-datasets/era-interim).

Code availability: The Matlab code used in this paper is available as long as authors are contacted.

Ethics approval: Ethics approval is not required for this study.

Consent to participate: Consent to participate is not required for this study.

Consent for publication: Consent for publication is not required for this study. 


\section{References}

Anderson BT, Feldl N, Lintner BR (2018) Emergent behavior of Arctic precipitation in response to enhanced Warming. J. Geophys. Res. Atmos. 123: 2704-2717

Auger JD, Birkel SD, Maasch KA, Mayewski PA, Schuenemann KC (2017)

Examination of precipitation variability in southern Greenland. J. Geophys. Res. Atmos. 122:6202-6216

Barnston AG, Livezey RE (1987) Classification, seasonality and persistence of low-frequency atmospheric circulation patterns. Mon. Wea. Rev. 115:1083-1126

Barrett AP, Stroeve JC, Serreze MC. (2020) Arctic Ocean Precipitation From Atmospheric Reanalyses and Comparisons With North Pole Drifting Station Records. J. Geophys. Res.: Oceans, 125: e2019JC015415.

Barry RG, Serreze MC (2000) Atmospheric components of the Arctic Ocean freshwater balance and their interannual variability, in The Freshwater Budget of the Arctic Ocean, edited by E. L. Lewis et al., pp. 45-56, Springer, New York.

Behrangi A, Lebsock M, Wong S, Lambrigtsen B (2012) On the quantification of oceanic rainfall using space borne sensors. J. Geophys. Res. 117: D20105

Behrangi A, Christensen M, Richardson M, Lebsock M, Stephens G, Huffman GJ, Bolvin D, Adler RF, Gardner A, Lambrigtsen B, Fetzer E (2016) Status of high-latitude precipitation estimates from observations and reanalyses. J. Geophys. Res. Atmos. 121:4468-4486

Bengtsson L, Hodges K, Koumoutsaris S, Zahn M, Keenlyside N (2011) The changing atmospheric water cycle in polar regions in a warmer climate. Tellus, 
63A:907-920

Bintanja R, Selten F (2014) Future increases in Arctic precipitation linked to local evaporation and sea-ice retreat. Nature 509:479-482

Boisvert LN, Stroeve JC. (2015) The Arctic is becoming warmer and wetter as revealed by the Atmospheric Infrared Sounder. Geophys. Res. Lett.

$42: 4439-4446$

Boisvert LN, Webster MA, Petty AA, Markus T, Bromwich DH, Cullather DH (2018) Intercomparison of precipitation estimates over the Arctic Ocean and its peripheral seas. J. Climate 31:8441-8462Cai M (2005) Dynamic amplification of polar warming. Geophys. Res. Lett.

32:L22710

Cassano JJ, Uotila P, Lynch AH, Cassano EN (2007) Predicted changes in synoptic forcing of net precipitation in large Arctic river basins during the $21^{\text {st }}$ century. $\mathrm{J}$. Geophys. Res. 112:G04S49

Dee DP, Uppala SM, Simmons AJ., Berrisford P, Poli P, Kobayashi S, Andrae U, Balmaseda MA, Balsamo G, Bauer P, Bechtold P, Beljaars ACM, van de Berg L, Bidlot J, Bormann N, Delsol C, Drgani R, Fuentes M, Geer AJ, Haimberger L, Healy SB, Hersbach H, Hólm EV, Isaksen L, Kållberg P, Köhler M, Matricardi M, McNally AP, Monge-Sanz BM, Morcrette JJ., Park B-K, Peubey C, de Rosnay P, Tavolato C, Thépaut J-N, Vitart F (2011) The ERA-Interim reanalysis: configuration and performance of the data assimilation system. Quart. J. Roy. Meteor. Soc. 137:553-597 
Deser C, Tomas RA, Sun L. (2015) The role of ocean-atmosphere coupling in the zonal-mean atmospheric response to Arctic sea ice loss. J. Climate 28: $2168-2186$.

Ding Q, Schweiger AJB, L'Heureux ML, Battisti DS, Johnson NC, Blanchard-Wrigglesworth E, Zhang Q, Harnos K, Eastman RM, Steig EJ (2017) Influence of high-latitude atmospheric circulation changes onsummertime Arctic sea ice. Nat. Climate Change 7:289-295

Fearon MG, Doyle JD, Ryglicki DR, Finocchio PM, Sprenger M (2020) The role of cyclones in moisture transport into the Arctic. Geophys. Res. Lett. doi:10.1029/2020GL090353

Ghatak D, Deser C, Frei A, Gong G, Phillips A, Robinson DA, Stroeve J (2012) Simulated Siberian snow cover response to observed Arctic sea ice loss. 1979-2008. J. Geophys. Res. 117:D23108

Gibson PB, Perkins-Kirkpatrick SE, Uotila P, Pepler AS, Alexander LV (2017) On the use of self-organizing maps for studying climate extremes. J. Geophys. Res. Atmos. 122:3891-3903

Glisan JM, Gutowksi Jr WJ (2014a) WRF winter extreme daily precipitation over the North American CORDEX Arctic. J. Geophys. Res. Atmos. 119:10738-10748

Glisan JM, Gutowksi Jr WJ (2014b) WRF summer extreme daily precipitation over the CORDEX Arctic. J. Geophys. Res. Atmos. 119:1720-1732

Glisan JM, Gutowski Jr WJ, Cassano JJ, Cassano EN, Seefeldt MW (2016) Analysis 
of WRF extreme daily precipitation over Alaska using self-organizing maps. J. Geophys. Res.Atmos. 121:7746-7761

Groves DG, Francis JA (2002) Moisture hudget of the Arctic atmosphere from TOVS satellite data. J. Geophys. Res. 107:4391

Hakuba MZ Folini D, Wild M, Schär C (2012) Impact of Greenland's topographic height on precipitation and snow accumulation in idealized simulations. J. Geophys. Res. 117:D09107

Hanssen-Bauer I, Førland EJ (1998) Long-Term Trends in precipitation and pemperature in the Norwegian Arctic: Can They Be Explained by Changes in Atmospheric Circulation Patterns?. Clim. Res. 10:143-153

Hegyi BM, Deng Y (2011) A dynamical fingerprint of tropical Pacific sea surface temperature on the decadal-scale variability of cool-season Arctic precipitation. J. Geophys. Res. 116:D20121

Heikkilä U, Sorteberg A (2012) Characteristics of autumn-winter extreme precipitation on the Norwegian west coast identified by cluster analysis. Clim. Dyn. 39:929-939

Held I, Soden B (2006) Robust response of the hydrological cycle to global warming. J. Climate 19:5686-5699

Henderson G, Peings Y, Furtado JC, Kushner PJ (2018) Snow-atmosphere coupling in the Northern Hemisphere. Nature Climate Change 8:954-963

Holland MM, Barrett AP, Serreze MC (2007) Projected changes in Arctic ocean freshwater budgets. J. Geophys. Res. 112:G04S55 
Higgins ME, Cassano JJ (2009) Impacts of reduced sea ice on winter Arctic atmospheric circulation, precipitation, and temperature. J. Geophys. Res. 114:D16107

Hwang Y-T, Frierson D (2010) Increasing atmospheric poleward energy with global warming. Geophys. Res. Lett. 37:L24807

Kane DL, McNamara JP, Yang D, Olsson PQ, Gieck RE (2003) An extreme rainfall/runoff event in Arctic Alaska. J. Hydrometeorology 4:1220-1228

Kattsov VM, Walsh JE (2000) Twentieth-century trends of Arctic precipitation from observational data and a climate model simulation. J. Climate 13:1362-1370

Kattsov VM, Walsh JE, Chapman WL, Govorkova VA, Pavlova TV, Zhang X (2007) Simulation and projection of Arctic freshwater budget components by the IPCC AR4 global climate models. J. Climate 8:571-589

Khon VC, Mokhov II, Roeckner E, Semenov VA (2007) Regional changes of precipitation characteristics in Northern Eurasia from simulations with global climate model. Global Planet. Change 57:118-123

Kohonen T (2001) Self-Organizing Maps. 3rd ed. Springer, 501 pp

Kopec BG, Feng X, Michel FA, Posmentier ES (2016) Influence of sea ice on Arctic precipitation, Proc. Natl. Acad. Sci. USA 113:46-51

Lader R, Bhatt US, Walsh JE, Rupp TS, Bieniek PA (2016) Two-meter temperature and precipitation from atmospheric reanalysis evaluated for Alaska. J. Appl. Meteorol. Clim. 55:901-922

Lee S, Feldstein SB (2013) Detecting ozone- and greenhouse gas-driven wind trends 
with observational data. Science 339:563-567

Legates D, Willmott C (1990) Mean seasonal and spatial variability in gauge-corrected global precipitation. Int. J. Climatol. 10:111-127

Lindsay R, Wensnahan M, Schweiger A, Zhang J (2014) Evaluation of seven different atmospheric reanalysis products in the Arctic. J. Climate 27:2588-2606

Lique C, Holland MM, Dibike YB, Lawrence DM, Screen JA (2016) Modeling the Arctic freshwater system and its integration in the global system: Lessons learned and futurechallenges. J. Geophys. Res. Biogeosci. 121:540-566

Liston GE, Hiemstra CA (2011) The changing crosphere: Pan-Arctic snow trends. J.

Climate 24:5691-5712

McAfee SA, Guentchev G, Eischeid JK (2013) Reconciling precipitation trends in Alaska: 1. Station based analyses. J. Geophys. Res. Atmos. 118:7523-7541

McAfee S, Guentchev G, Eischeid J (2014) Reconciling precipitation trends in Alaska: 2. Gridded data analyses. J. Geophys. Res. Atmos. 119:13820-13837

Meehl GA, Arblaster JM, Tebaldi C (2005) Understanding future patterns of increased precipitation intensity in climate model simulations. Geophys. Res. Lett.

32:L18719

Min S-K, Zhang X, Zwiers F (2008) Human-induced Arctic moistening, Science $320: 518-520$

Mioduszewski JR, Rennermalm AK, Hammann A, Tedesco M, Noble EU, Stroeve JC, Mote TL (2016) Atmospheric drivers of Greenland surface melt revealed by self-organizing maps. J. Geophys. Res. Atmos. 121:5095-5114 
Park H, Walsh JE, Kim Y, Nakai T, Ohata T (2013) The role of declining Arctic sea ice in recent decreasing terrestrial Arctic snow depths. Polar Science 7:174-187

Reusch DB, Alley RB, Hewitson BC (2005) Relative performance of self-organizing maps and principal component analysis in pattern extraction from synthetic climatological data. Polar Geogr. 29:188-212

Rignot E, Thomas RH (2002) Mass Balance of polar ice sheets. Science 297: $1502-1506$

Rinke A, Segger B, Crewell S, Maturilli M, Naakka T, Nygård T, Vihma T, Alshawaf F, Dick G, Wickert J, Keller J (2019) Trends of vertically integrated water vapor over the Arctic during 1979-2016: Consistent moistening all over? J. Climate $6097-6116$

Saha SK, Rinke A, Dethloff K (2006) Future winter extreme temperature and precipitation events in the Arctic. Geophys. Res. Lett. 33:L15818

Sammon J (1969) A non-linear mappings for data structure and analyses. IEEE Trans. Comput. 18:401-409

Schuenemann KC, Cassano JJ, Finnis J (2009) Synoptic forcing of precipitation over Greenland: Climatology for 1961-1999. J. Hydrometeorol.10:60-78

Screen JA, Simmonds I (2012) Declining summer snowfall in the Arctic: Causes, impacts and feedbacks. Clim. Dyn. 38:2243-2256

Serreze MC, Hurst CM (2000) Representation of mean Arctic precipitation from NCEP-NCAR and ERA reanalyses. J. Climate 13:182-201

Serreze MC, Crawford AD, Barrett AP (2015) Extreme daily precipitation events at 
Spitsbergen, an Arctic Island. Int. J. Climatol. 35:4574-4588

Serreze MC, Barrett AP, Lo F (2005) Northern high-latitude precipitation as depicted by atmospheric reanalyses and satellite retrievals. Mon. Wea. Rev.

$133: 3407-3430$

Serreze, M., and R. G. Barry, 2005: The Arctic Climate System. Cambridge University Press, 385pp.

Serreze MC, Barry R G (2011) Processes and impacts of Arctic amplification: a research synthesis. Global Planet Change 77:85-96

Stroeve JC, Serreze MC, Barrett A, Kindig DN (2011) Attribution of recent changes in autumn cyclone associated precipitation in the Arctic. Tellus 63A:653-663

Singh HKA, Bitz CM, Donohoe A, Rasch PJ (2017) A source-receptor perspective on the polar hydrologic cycle: Sources, seasonality, and Arctic-Antarctic parity in the hydrologic cycle response to $\mathrm{CO}_{2}$ doubling. J. Climate 30:9999-10017

Skific N, Francis J, Cassano J (2009a) Attribution of projected changes in atmospheric moisture transport in the Arctic: A self-organizing map perspective. J. Climate $22: 4135-4153$

Skific N, Francis J, Cassano J (2009b) Attribution of seasonal and regional changes in Arctic moisture convergence. J. Climate 22:5115-5134

Stephens GL, L'Ecuyer T, Forbes R, Gettlemen A, Golaz J-C, Bodas-Salcedo A, Suzuki K, Gabriel P, Haynes J (2010) Dreary state of precipitation in global models. J. Geophys. Res. 115:D24211

Stroeve JC, Serreze MC, Holland MM, Kay JE, Malanik J, Barrett AP (2012) The 
Arctic's rapidly shrinking sea ice cover: a research synthesis. Clim. Change 110:1005-1027

Trenberth KE (2011) Change in precipitation with climate change. Clim. Res. 47:123-138

Vavrus SJ, Holland MM, Jahn A, Bailey DA, Blazey BA (2012) Twenty-first-century Arctic climate change in CCSM4. J. Climate 25:2696-2710

Vihma T, Screen J, Tjernström M, Newton B, Zhang X, Popova V, Deser C, Holland M, Prowse T (2016) The atmospheric role in the Arctic water cycle: A review on processes, past and future changes, and their impacts. J. Geophys. Res.

Biogeosci. 121:586-620

Villamil-Otero GA, Zhang J, He J, Zhang X (2018) Role of extratropical cyclones in the recently observed increase in poleward moisture transport into the Arctic Ocean. Advances in Atmospheric Sciences 35:85-94

Wallace JM, Gutzler DS (1981) Teleconnections in the geopotential height field during the Northern Hemisphere winter. Mon. Wea. Rev. 109:784-812

Walsh JE, Kattsov V, Portis D, Meleshko V (1998) Arctic Precipitation andEvaporation: Model Results and Observational Estimates. J. Climate $11: 72-87$

Wang J, Zhang J, Watanabe E, Ikeda M, Mizobata K, Walsh JE, Bai X, Wu B (2009) Is the Dipole Anomaly a major driver to record lows in Arctic summer sea ice extent?. Geophys. Res. Lett. 36:L05706

Wu Q, Zhang J, zhang X, Tao W (2014) Interannual variability and long-term changes 
of atmospheric circulation over the Chukchi and Beaufort Seas. J. Climate $27: 4871-4889$

Yang D (1999) An improved precipitation climatology for the Arctic Ocean. Geophys.

Res. Lett. 26:1625-1628

Zahn M, Akperov M, Rinke A, Feser F, Mokhov II (2018) Trends of cyclone characteristics in the Arctic and their patterns fro mdifferent reanalysis data. J. Geophys. Res. 123:2737-2751

Zhang X, He J, Zhang J, Polyakov I, Gerdes R, Inoue J, Wu P (2013) Enhanced Poleward Atmospheric Moisture Transport Amplified Northern High-Latitude Wetting Trend. Nature Climate Change 3:47-51 
TABLE 1. Spatial correlations (Cors) between the monthly year-round Arctic sea ice concentration and the corresponding SOM pattern for each month from 1979 to 2018.

\begin{tabular}{|l|l|l|l|l|l|l|l|l|l|}
\hline & $3 \times 1$ & $2 \times 2$ & $3 \times 2$ & $4 \times 2$ & $3 \times 3$ & $5 \times 2$ & $4 \times 3$ & $5 \times 3$ & $4 \times 4$ \\
\hline Cor & 0.29 & 0.36 & 0.43 & 0.42 & 0.46 & 0.43 & 0.47 & 0.47 & 0.48 \\
\hline
\end{tabular}


Table 2. Percentage of days represented by each SOM node (or frequency of occurrence of each SOM node) for each season (\%)

\begin{tabular}{lllll}
\hline & MAM & JJA & SON & DJF \\
\hline Node 1 & 12.8 & 9.4 & 13.2 & 11.3 \\
Node 2 & 6.1 & 5.3 & 6.2 & 5.7 \\
Node 3 & 9.6 & 10.3 & 9.8 & 9.2 \\
Node 4 & 10.7 & 10.0 & 11.1 & 10.0 \\
Node 5 & 7.1 & 7.8 & 5.5 & 6.7 \\
Node 6 & 4.0 & 3.5 & 4.3 & 4.0 \\
Node 7 & 4.5 & 3.8 & 4.3 & 4.4 \\
Node 8 & 6.7 & 7.6 & 7.9 & 7.5 \\
Node 9 & 10.5 & 13.0 & 11.3 & 12.2 \\
Node 10 & 9.4 & 8.5 & 9.8 & 8.7 \\
Node 11 & 5.8 & 5.6 & 5.9 & 6.9 \\
Node 12 & 12.9 & 15.3 & 10.8 & 13.5 \\
\hline
\end{tabular}


Table 3. Trends in the time coefficients of each SOM node for each season $\left(\mathrm{yr}^{-1}\right)$. Asterisks indicate the above $95 \%$ confidence level.

\begin{tabular}{lllll}
\hline & \multicolumn{1}{c}{ MAM } & \multicolumn{1}{c}{ JJA } & \multicolumn{1}{c}{ SON } & \multicolumn{1}{c}{ DJF } \\
\hline Node 1 & 0.0019 & -0.0813 & -0.0665 & $0.2988^{*}$ \\
Node 2 & -0.0637 & -0.0252 & 0.0644 & 0.1024 \\
Node 3 & 0.0073 & $-0.2239^{*}$ & -0.0223 & 0.1151 \\
Node 4 & -0.1518 & -0.1343 & -0.1513 & $-0.1587^{*}$ \\
Node 5 & 0.0415 & 0.1563 & 0.0548 & 0.0460 \\
Node 6 & -0.0347 & 0.0396 & 0.0152 & 0.0311 \\
Node 7 & -0.0641 & -0.0375 & -0.0057 & 0.0207 \\
Node 8 & -0.0234 & -0.0698 & -0.1241 & $-0.1447^{*}$ \\
Node 9 & $0.2208^{*}$ & $0.3205^{*}$ & 0.0875 & 0.0152 \\
Node 10 & 0.0641 & $0.1521^{*}$ & 0.1540 & -0.1114 \\
Node 11 & 0.0433 & 0.0897 & 0.1047 & -0.0298 \\
Node 12 & 0.0413 & -0.1862 & -0.1107 & -0.1848 \\
\hline
\end{tabular}


Table 4. Trends in the grid-averaged seasonal precipitation (P) (units: $\mathrm{mm} \mathrm{yr}^{-1}$ ) and the number of days of extreme precipitation using the $95 \%$ percentile thresholds (E 95\%) (day $\mathrm{yr}^{-1}$ ) related to dynamic, thermodynamic and interaction components in spring. The grids chosen are those with significant trends.

\begin{tabular}{cllllll}
\hline Node & \multicolumn{2}{c}{ Dynamic } & \multicolumn{2}{c}{ Thermodynamic } & \multicolumn{2}{c}{ Interaction } \\
& \multicolumn{1}{c}{$\mathrm{P}$} & $\mathrm{E} \mathrm{95 \%}$ & $\mathrm{P}$ & $\mathrm{E} \mathrm{95 \%}$ & $\mathrm{P}$ & $\mathrm{E} \mathrm{95 \%}$ \\
\hline 1 & 0.0001 & 0.0001 & -0.0002 & 0.0025 & -0.0002 & -0.0004 \\
2 & -0.0052 & -0.0025 & 0.0025 & 0.0016 & -0.0012 & -0.0000 \\
3 & 0.0007 & 0.0005 & 0.0042 & 0.0104 & -0.0002 & -0.0007 \\
4 & -0.0167 & -0.0126 & 0.0038 & 0.0103 & -0.0001 & -0.0024 \\
5 & 0.0030 & 0.0013 & 0.0003 & 0.0005 & 0.0003 & -0.0003 \\
6 & -0.0023 & -0.0010 & 0.0005 & 0.0015 & 0.0007 & 0.0005 \\
7 & -0.0055 & -0.0027 & 0.0013 & 0.0027 & 0.0009 & 0.0011 \\
8 & -0.0022 & -0.0014 & 0.0010 & 0.0067 & 0.0031 & -0.0010 \\
9 & 0.0156 & 0.0070 & 0.0108 & 0.0077 & -0.0041 & -0.0014 \\
10 & 0.0060 & 0.0033 & -0.0022 & -0.0025 & 0.0024 & 0.0008 \\
11 & 0.0036 & 0.0019 & 0.0037 & 0.0038 & -0.0008 & 0.0010 \\
12 & -0.0039 & -0.0027 & 0.0124 & 0.0166 & -0.0070 & -0.0058 \\
Total & -0.0068 & -0.0088 & 0.0381 & 0.0618 & -0.0062 & 0.0086 \\
\hline
\end{tabular}




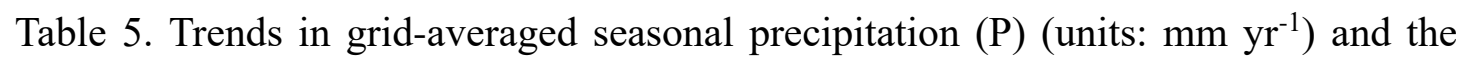
number of days of extreme precipitation using the $95 \%$ percentile thresholds (E 95\%) $\left(\right.$ day $\mathrm{yr}^{-1}$ ) related to dynamic, thermodynamic and interaction components in summer. The grids chosen are those with significant trends.

\begin{tabular}{cllllll}
\hline Node & \multicolumn{2}{c}{ Dynamic } & \multicolumn{2}{c}{ Thermodynamic } & \multicolumn{2}{c}{ Interaction } \\
& \multicolumn{1}{c}{$\mathrm{P}$} & $\mathrm{E} 95 \%$ & $\mathrm{P}$ & $\mathrm{E} 95 \%$ & \multicolumn{1}{c}{$\mathrm{P}$} & $\mathrm{E} 95 \%$ \\
\hline 1 & -0.0166 & -0.0038 & -0.0014 & 0.0003 & -0.0048 & -0.0034 \\
2 & -0.0049 & -0.0012 & -0.0038 & -0.0003 & -0.0008 & -0.0004 \\
3 & -0.0445 & -0.0109 & -0.0017 & 0.0004 & -0.0025 & -0.0015 \\
4 & -0.0255 & -0.0061 & -0.0094 & -0.0029 & 0.0031 & 0.0012 \\
5 & 0.0279 & 0.0064 & 0.0052 & 0.0025 & -0.0037 & -0.0014 \\
6 & 0.0078 & 0.0019 & -0.0041 & -0.0019 & -0.0004 & 0.0005 \\
7 & -0.0061 & -0.0013 & -0.0066 & -0.0021 & 0.0042 & 0.0008 \\
8 & -0.0142 & -0.0033 & 0.0003 & -0.0004 & -0.0009 & 0.0003 \\
9 & 0.0557 & 0.0146 & 0.0045 & -0.0035 & 0.0023 & -0.0003 \\
10 & 0.0303 & 0.0085 & -0.0046 & -0.0029 & 0.0050 & 0.0012 \\
11 & 0.0184 & 0.0050 & -0.0003 & -0.0011 & 0.0000 & -0.0000 \\
12 & -0.0386 & -0.0108 & -0.0111 & -0.0058 & 0.0075 & 0.0047 \\
Total & -0.0103 & -0.0010 & -0.0330 & -0.0177 & 0.0090 & 0.0017 \\
\hline
\end{tabular}




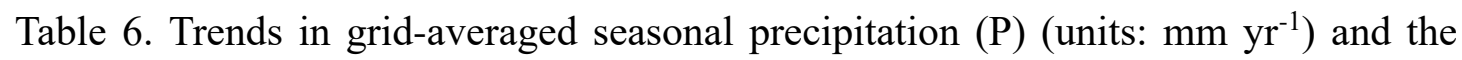
number of days of extreme precipitation using the $95 \%$ percentile thresholds (E 95\%) $\left(\right.$ day $\mathrm{yr}^{-1}$ ) related to dynamic, thermodynamic and interaction components in autumn. The grids chosen are those with significant trends.

\begin{tabular}{cllllll}
\hline & \multicolumn{2}{c}{ Dynamic } & \multicolumn{2}{c}{ Thermodynamic } & \multicolumn{2}{c}{ Interaction } \\
& \multicolumn{1}{c}{$\mathrm{P}$} & $\mathrm{E} 95 \%$ & $\mathrm{P}$ & $\mathrm{E} 95 \%$ & $\mathrm{P}$ & $\mathrm{E} 95 \%$ \\
\hline 1 & -0.0055 & -0.0025 & 0.0140 & 0.0079 & -0.0051 & -0.0016 \\
2 & 0.0058 & 0.0024 & 0.0035 & 0.0041 & 0.0007 & -0.0002 \\
3 & -0.0022 & -0.0010 & 0.0128 & 0.0078 & -0.0023 & -0.0002 \\
4 & -0.0160 & -0.0072 & -0.0006 & -0.0009 & 0.0013 & -0.0000 \\
5 & 0.0046 & 0.0021 & 0.0043 & 0.0030 & -0.0005 & 0.0000 \\
6 & 0.0014 & 0.0006 & 0.0036 & 0.0036 & 0.0023 & 0.0003 \\
7 & -0.0006 & -0.0003 & 0.0040 & 0.0039 & 0.0023 & 0.0014 \\
8 & -0.0141 & -0.0066 & 0.0025 & 0.0052 & 0.0026 & 0.0009 \\
9 & 0.0087 & 0.0045 & 0.0134 & 0.0093 & 0.0018 & 0.0045 \\
10 & 0.0176 & 0.0093 & 0.0062 & 0.0083 & 0.0029 & 0.0006 \\
11 & 0.0117 & 0.0061 & 0.0073 & 0.0081 & -0.0011 & -0.0011 \\
12 & -0.0126 & -0.0064 & 0.0025 & 0.0041 & 0.0039 & 0.0024 \\
Total & -0.0012 & 0.0010 & 0.0735 & 0.0644 & 0.0088 & 0.0070 \\
\hline
\end{tabular}


Table 7. Trends in grid-averaged seasonal precipitation (P) (units: $\mathrm{mm} \mathrm{yr}^{-1}$ ) and the number of days of extreme precipitation using the $95 \%$ percentile thresholds (E 95\%) (day $\mathrm{yr}^{-1}$ ) related to dynamic, thermodynamic and interaction components in winter. The grids chosen are those with significant trends.

\begin{tabular}{cllllll}
\hline & \multicolumn{2}{c}{ Dynamic } & \multicolumn{2}{c}{ Thermodynamic } & \multicolumn{2}{c}{ Interaction } \\
& \multicolumn{1}{c}{$\mathrm{P}$} & $\mathrm{E} \mathrm{95 \%}$ & $\mathrm{P}$ & $\mathrm{E} 95 \%$ & $\mathrm{P}$ & $\mathrm{E} 95 \%$ \\
\hline 1 & 0.0209 & 0.0172 & 0.0144 & 0.0156 & -0.0005 & -0.0012 \\
2 & 0.0066 & 0.0046 & 0.0073 & 0.0061 & -0.0004 & 0.0010 \\
3 & 0.0094 & 0.0082 & 0.0008 & 0.0013 & 0.0017 & -0.0006 \\
4 & -0.0138 & -0.0121 & 0.0043 & 0.0093 & -0.0013 & -0.0022 \\
5 & 0.0022 & 0.0015 & 0.0011 & 0.0020 & 0.0013 & 0.0010 \\
6 & 0.0016 & 0.0010 & 0.0007 & -0.0001 & 0.0029 & 0.0034 \\
7 & 0.0012 & 0.0009 & 0.0034 & 0.0049 & 0.0004 & -0.0012 \\
8 & -0.0097 & -0.0063 & 0.0030 & 0.0029 & 0.0003 & 0.0014 \\
9 & 0.0008 & 0.0006 & 0.0100 & 0.0136 & -0.0028 & -0.0055 \\
10 & -0.0063 & -0.0043 & 0.0021 & 0.0030 & 0.0029 & 0.0017 \\
11 & -0.0017 & -0.0011 & 0.0041 & 0.0038 & -0.0022 & -0.0017 \\
12 & -0.0104 & -0.0064 & 0.0031 & -0.0003 & 0.0003 & -0.0010 \\
Total & 0.0008 & 0.0621 & 0.0513 & 0.0621 & 0.0026 & -0.0049 \\
\hline
\end{tabular}


Figure captions

Figure 1 Climatology of seasonal total precipitation (units: $\mathrm{mm}$ ) for spring (March-may) (a), summer (June-August) (b), autumn (September-November) (c), and winter (December-February) (d) for the 1979-2016 period.

Figure 2 Ratios of the seasonal extreme precipitation amount to the seasonal total precipitation amount for spring (a), summer (b), autumn (c), and winter (d) for the 1979-2016 period.

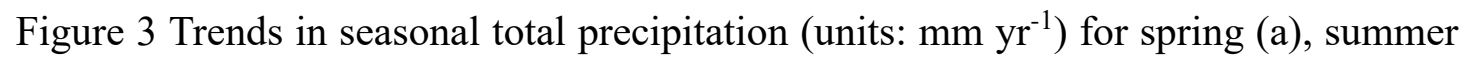
(b), autumn (c), and winter (d) for the 1979-2016 period. Dotted regions indicate the above $95 \%$ confidence level.

Figure 4 The same as Figure 3, but for ratios of the seasonal extreme precipitation amount to the seasonal total precipitation amount (units: yr-1)

Figure 5 The same as Figure 3, but for the number of days (units: day $\mathrm{yr}^{-1}$ ) of the seasonal extreme precipitation occurrences.

Figure 6 . The spring 500-hPa geopotential height (gpm) anomaly patterns on the $4 \times 3$ SOM nodes.

Figure 7. The summer 500-hPa geopotential height (gpm) anomaly patterns on the $4 \times 3$ SOM nodes.

Figure 8 . The autumn 500 -hPa geopotential height (gpm) anomaly patterns on the $4 \times 3$ SOM nodes.

Figure 9 . The winter $500-\mathrm{hPa}$ geopotential height (gpm) anomaly patterns on the $4 \times 3$ SOM nodes. 
Figure 10 . Spring daily precipitation anomaly $\left(\mathrm{mm} \mathrm{day}^{-1}\right)$ associated with the $4 \times 3$ SOM nodes.

Figure 11. Autumn daily precipitation anomaly ( $\mathrm{mm}$ day-1) associated with the $4 \times 3$ SOM nodes.

Figure 12 . Winter daily precipitation anomaly (mm day-1) associated with the $4 \times 3$ SOM nodes.

Figure 13. Trends in seasonal precipitation (upper panel) and in the number of days of extreme precipitation (lower panel) averaged over all grid points in a node where trends are significant.

Figure 14. Percentages of trends in seasonal total precipitation amount (upper) and the number of days of extreme precipitation (lower) explained by the thermodynamic, dynamic and interaction components for spring (red), summer (blue), autumn (yellow), and winter (black).

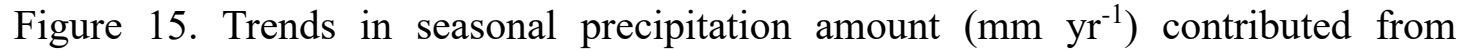
thermodynamic (top), dynamic (middle), and interaction (bottom) components for each season.

Figure 16. Same as Figure 13, but for the number of days of extreme precipitation occurrence.

Figure 17. Trends in seasonal total column water vapor $\left(\mathrm{kg} \mathrm{m}^{-2} \mathrm{yr}^{-1}\right)$ for spring (a), summer (b), autumn (c), and winter (d). 

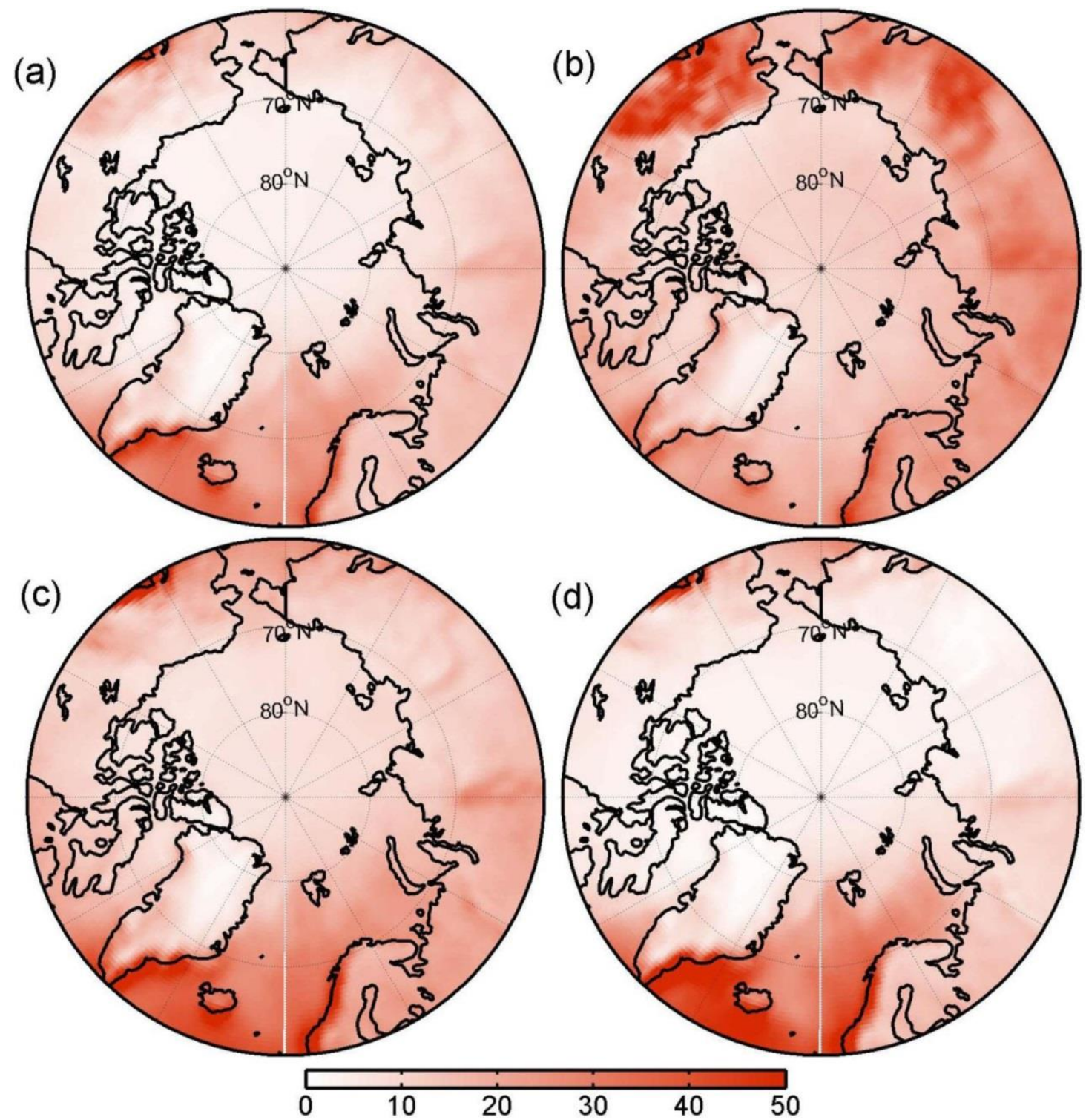

Figure 1 Climatology of seasonal total precipitation (units: $\mathrm{mm}$ ) for spring (March-May) (a), summer (June-August) (b), autumn (September-November) (c), and winter (December-February) (d) for the 1979-2016 period. 


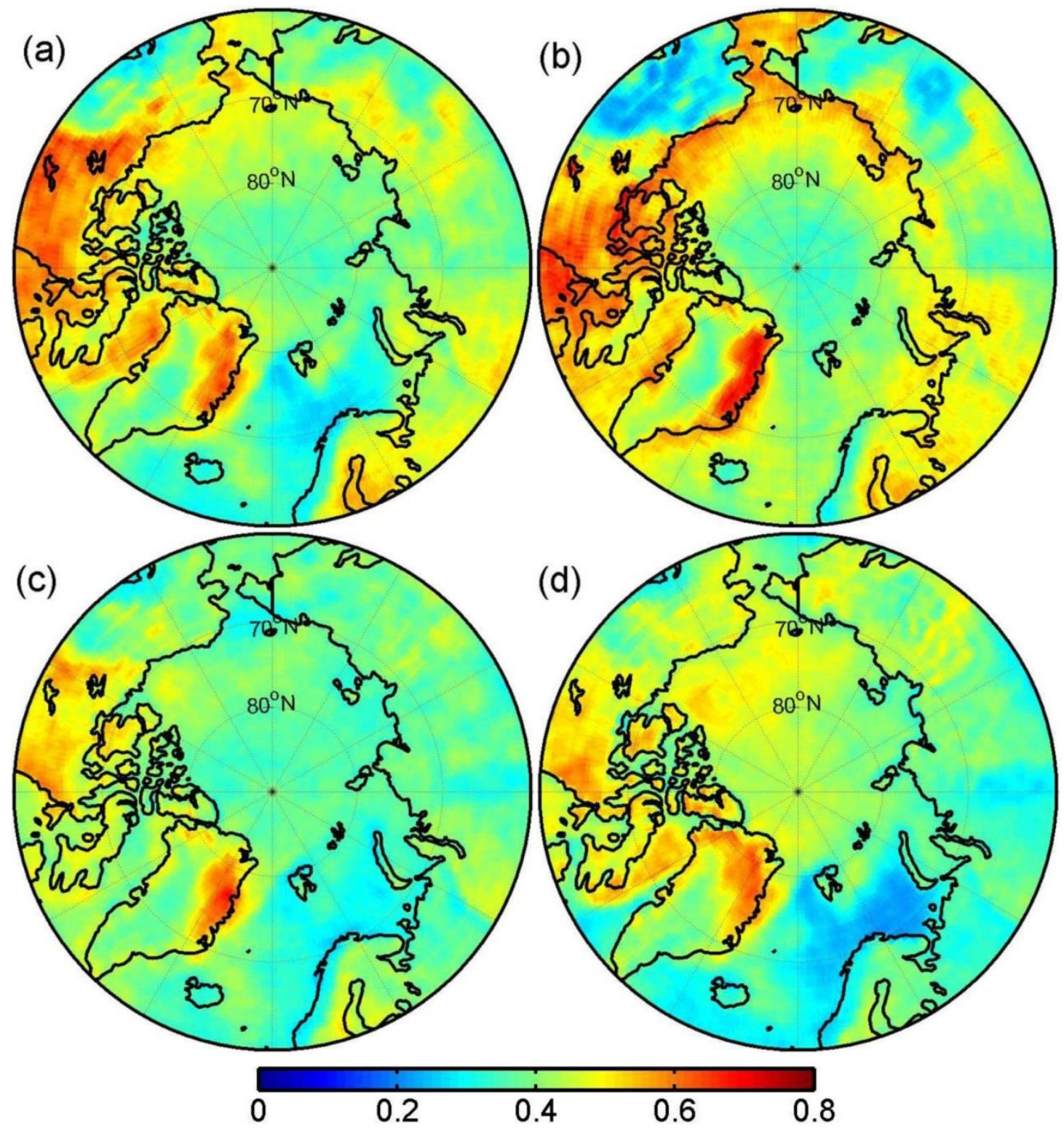

Figure 2 Ratios of the seasonal extreme precipitation amount to the seasonal total precipitation amount for spring (a), summer (b), autumn (c), and winter (d) for the 1979-2016 period. 


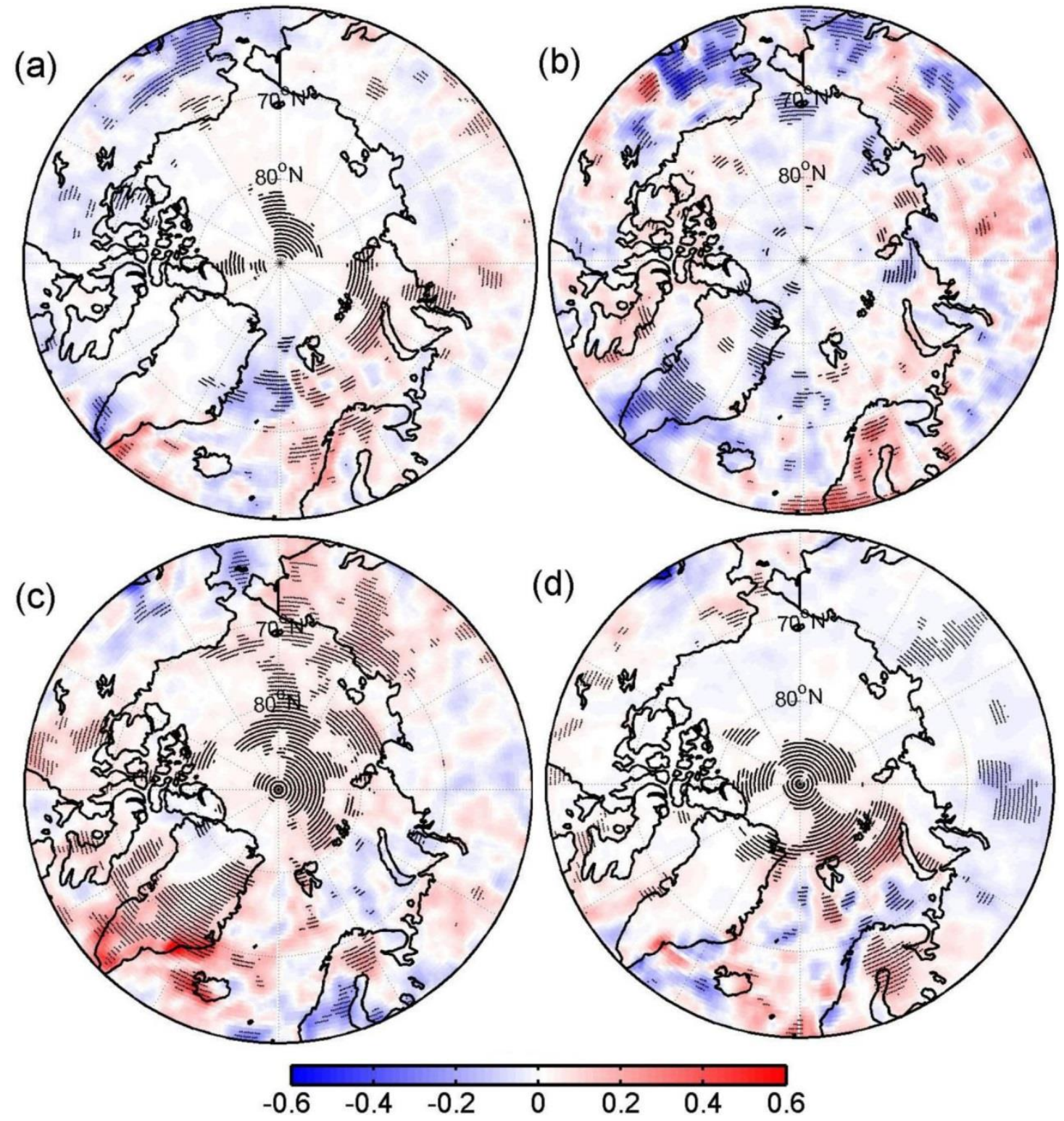

Figure 3 Trends in seasonal total precipitation (units: $\mathrm{mm} \mathrm{yr}^{-1}$ ) for spring (a), summer (b), autumn (c), and winter (d) for the 1979-2016 period. Dotted regions indicate the above $95 \%$ confidence level. 

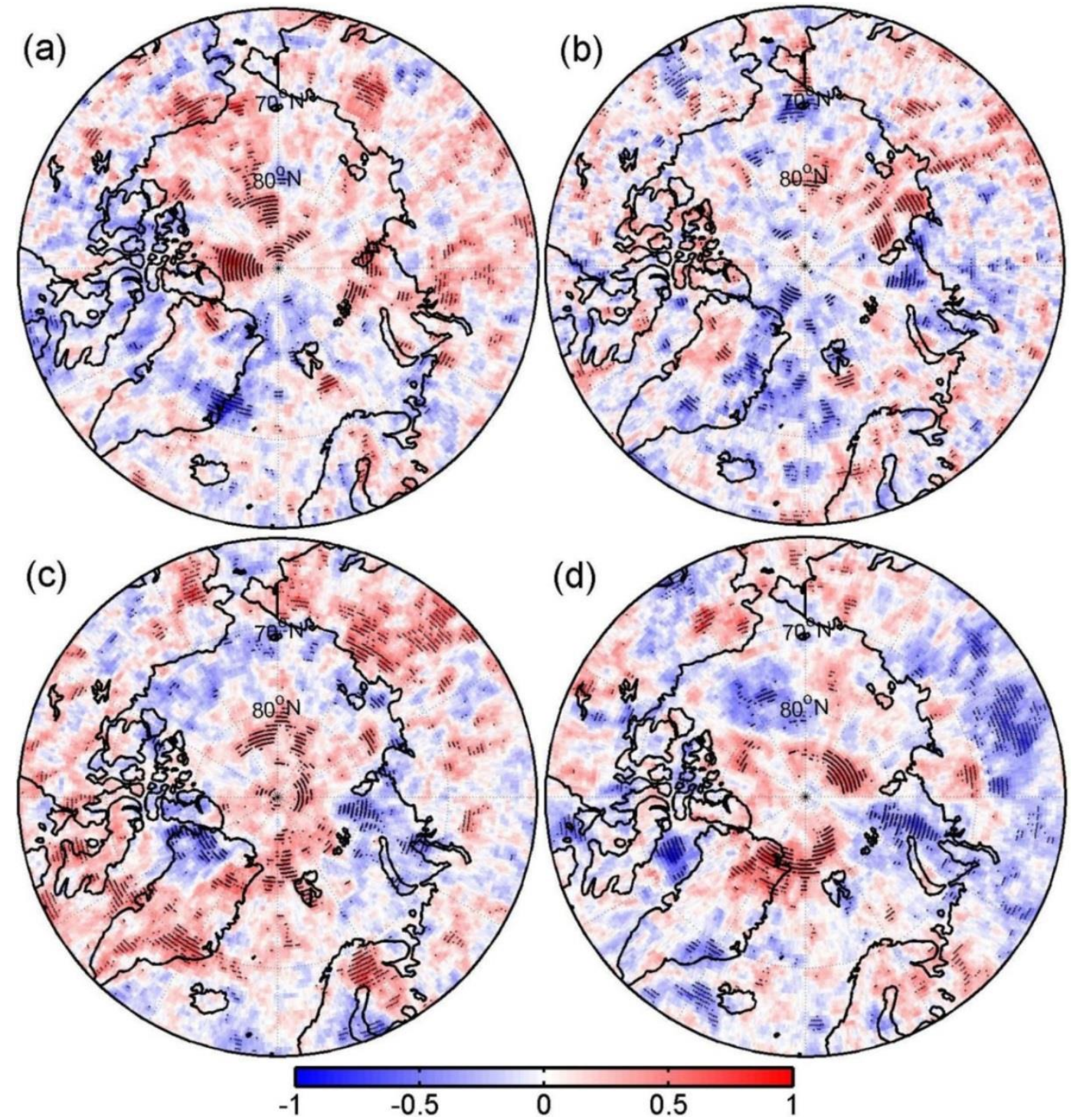

Figure 4 The same as Figure 3, but for ratios of the seasonal extreme precipitation amount to the seasonal total precipitation amount (units: $\mathrm{yr}^{-1}$ ) 


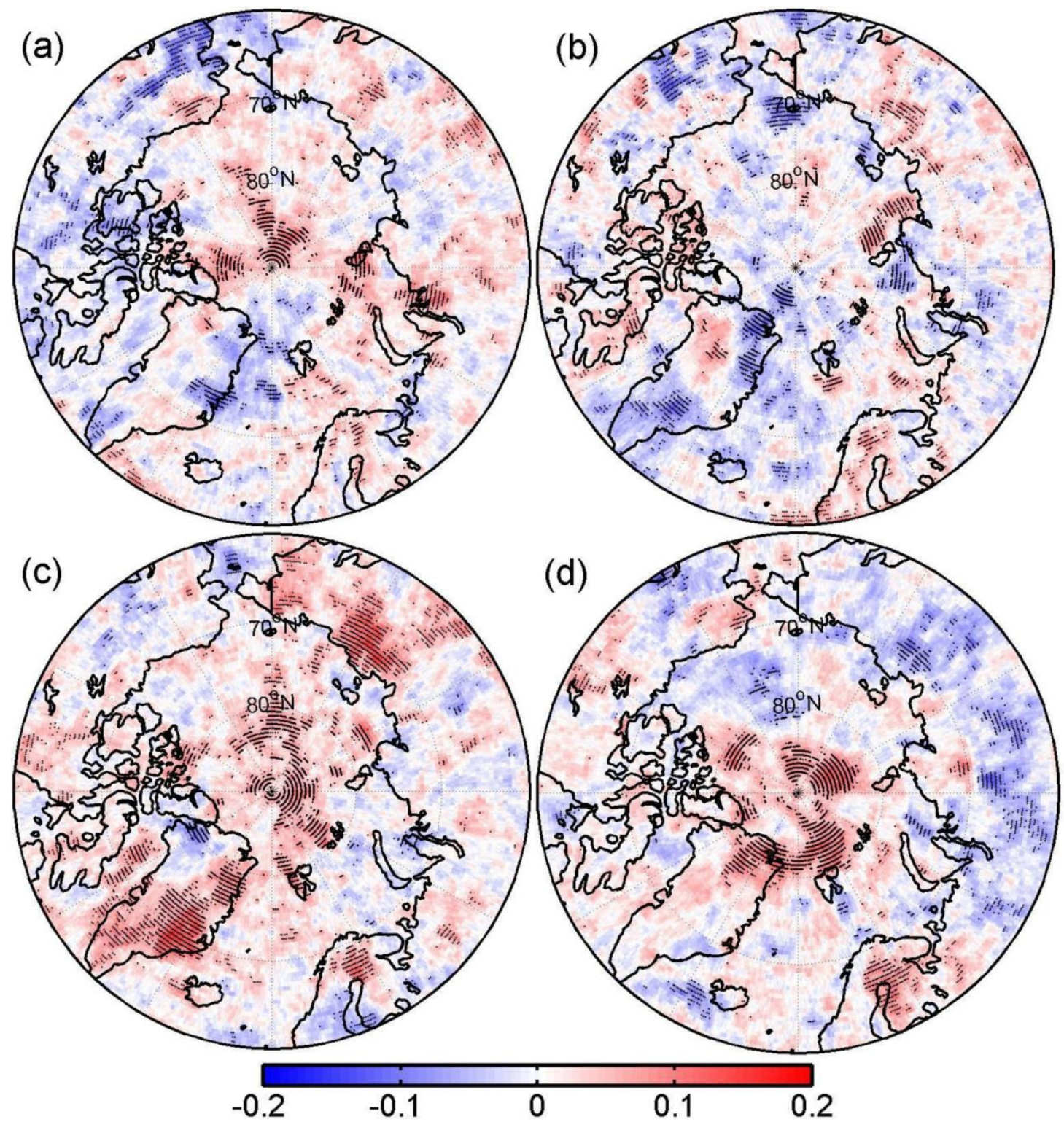

Figure 5 The same as Figure 3, but for the number of days (units: day $\mathrm{yr}^{-1}$ ) of the seasonal extreme precipitation occurrences. 


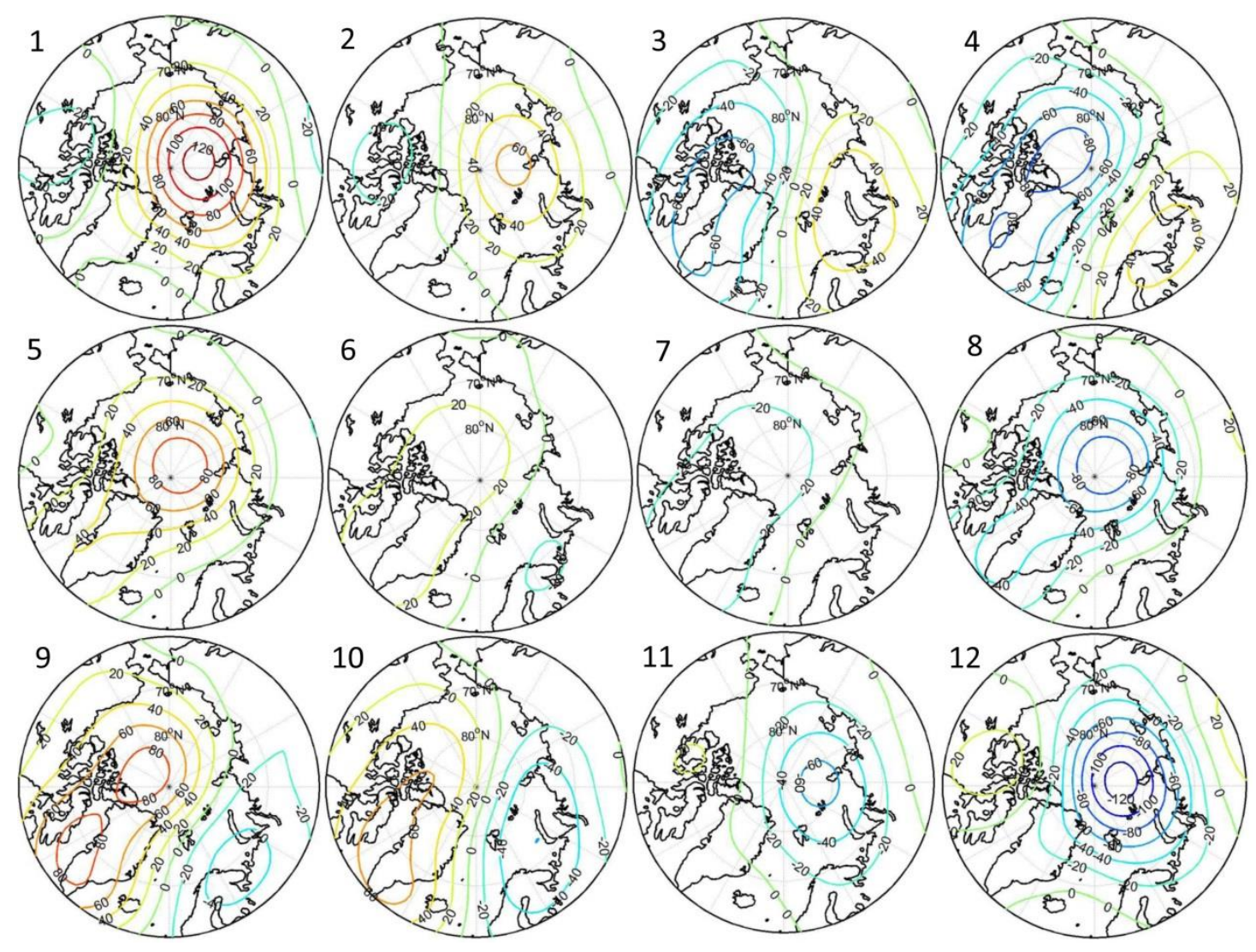

Figure 6 . The spring $500-\mathrm{hPa}$ geopotential height (gpm) anomaly patterns on the $4 \times 3$ SOM nodes. 

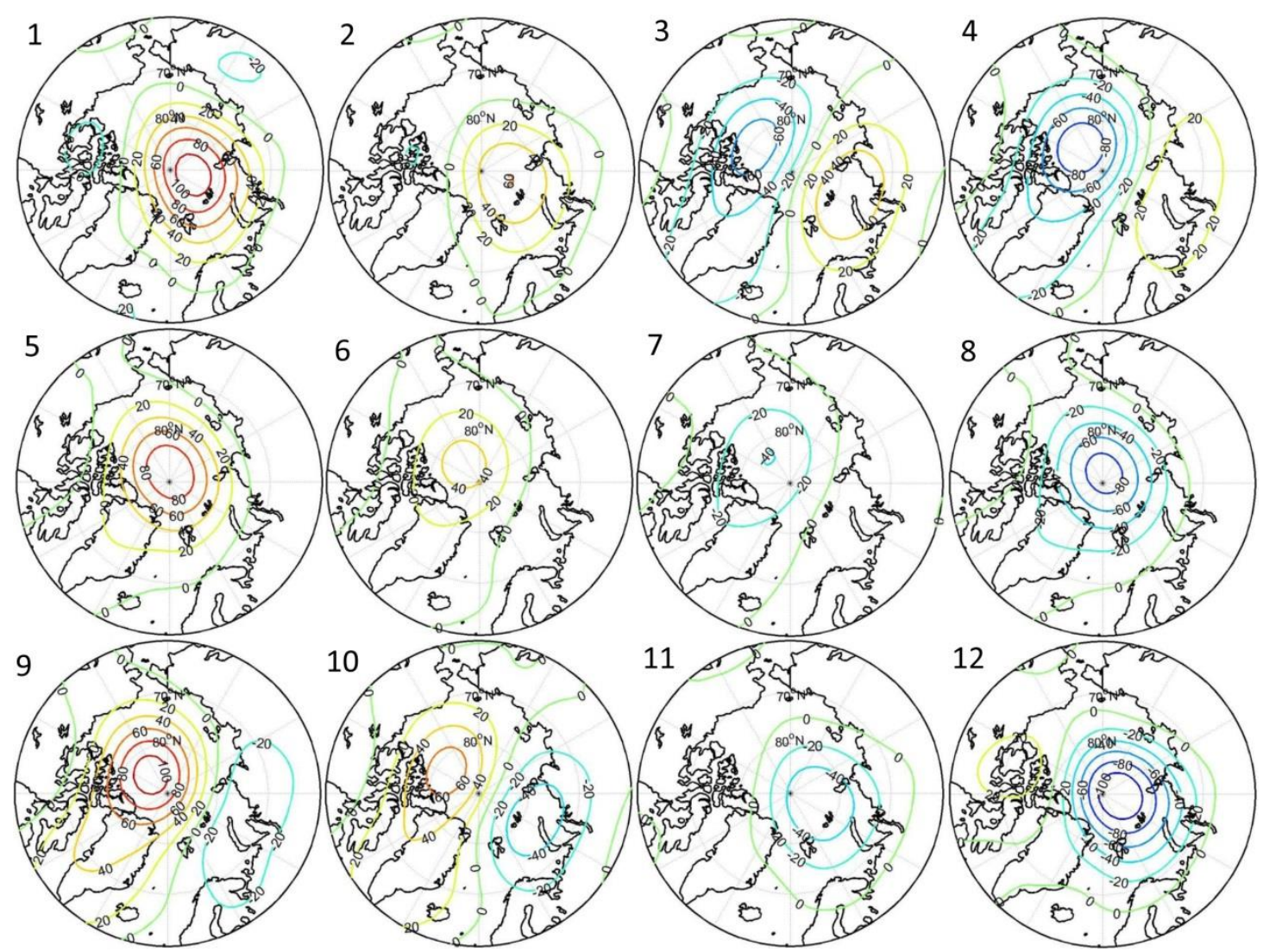

Figure 7. The summer $500-\mathrm{hPa}$ geopotential height (gpm) anomaly patterns on the $4 \times 3$ SOM nodes. 


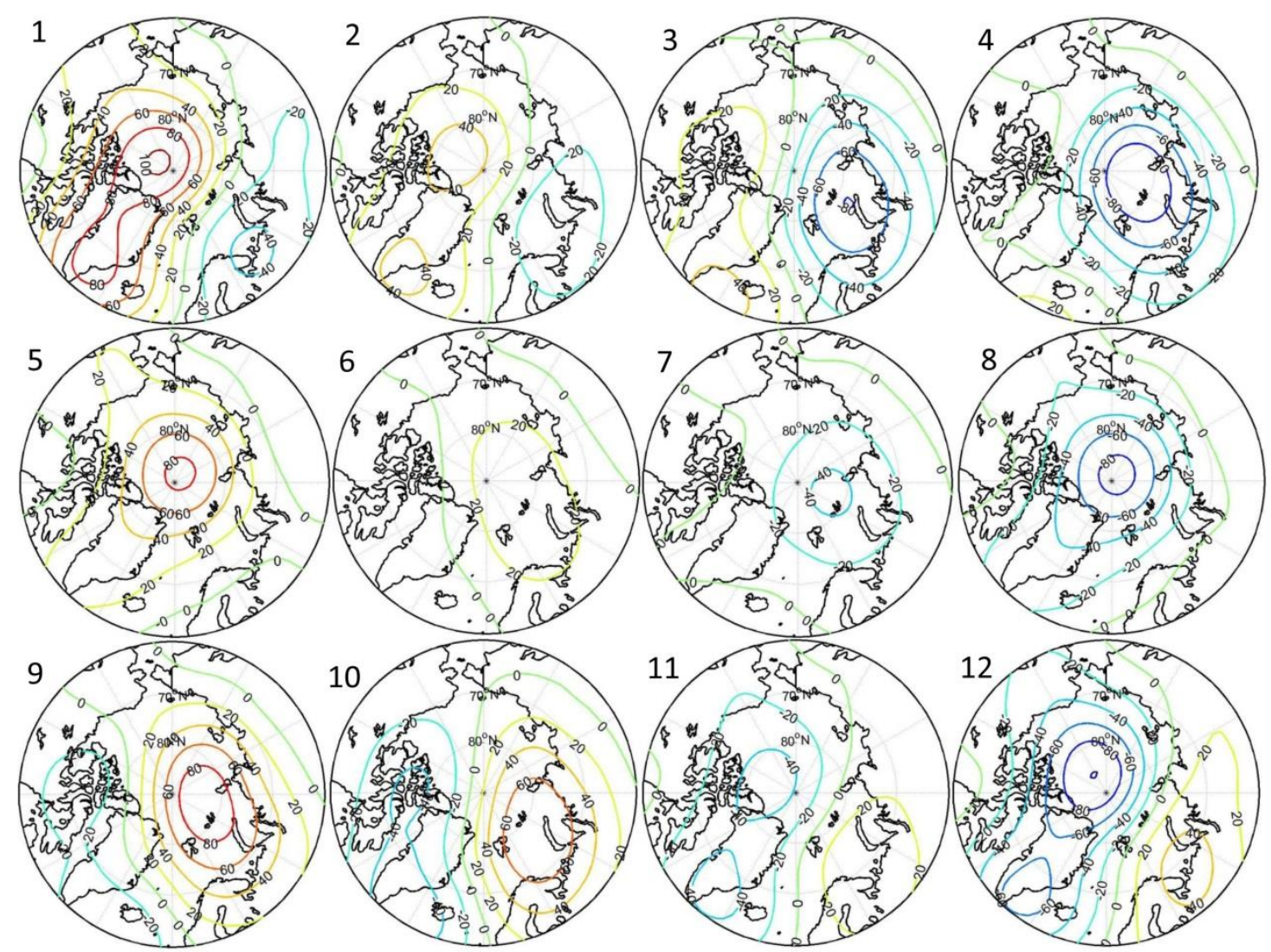

Figure 8 . The autumn 500 -hPa geopotential height (gpm) anomaly patterns on the $4 \times 3$ SOM nodes. 


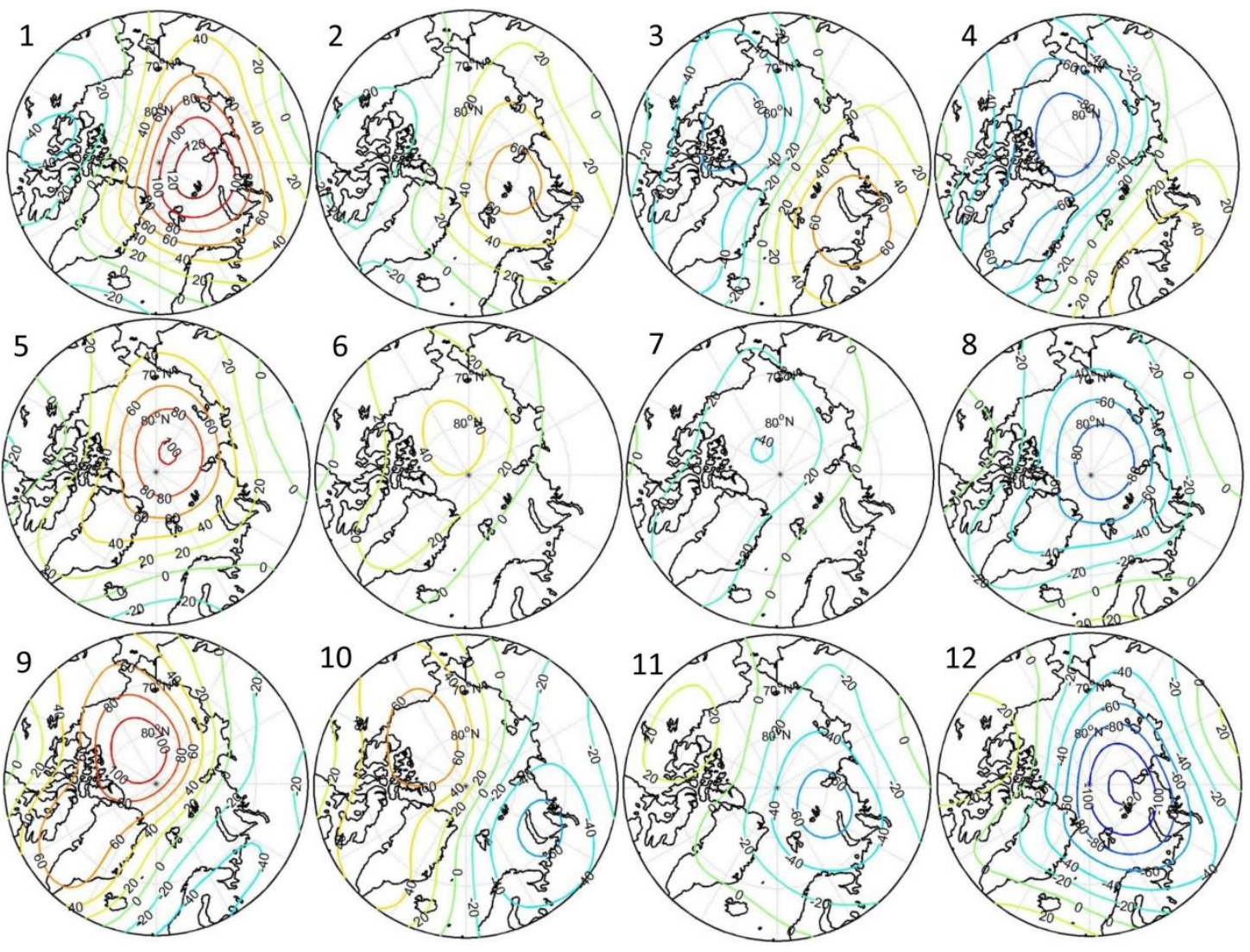

Figure 9 . The winter $500-\mathrm{hPa}$ geopotential height (gpm) anomaly patterns on the $4 \times 3$ SOM nodes. 


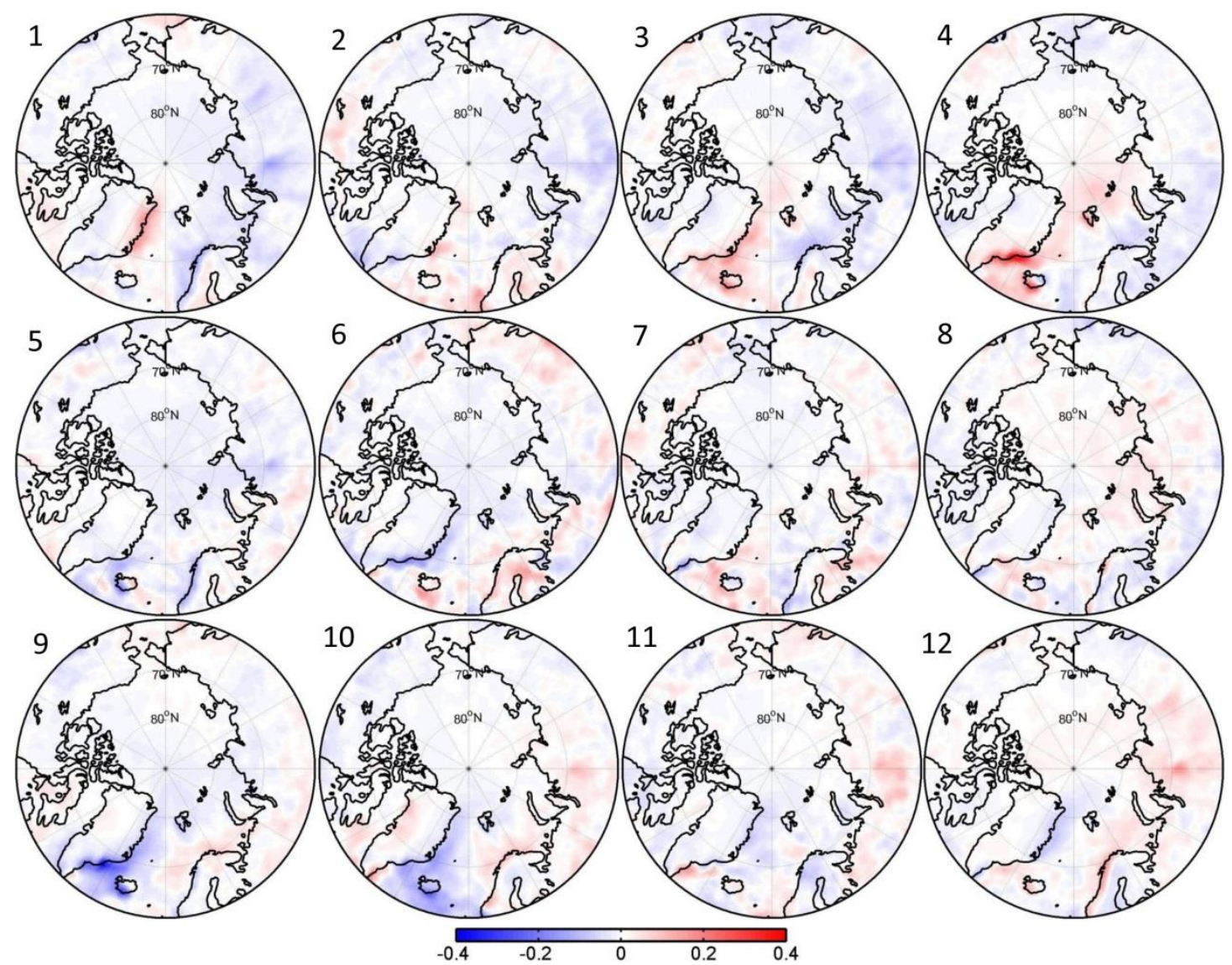

Figure 10. Spring daily precipitation anomaly $\left(\mathrm{mm} \mathrm{day}^{-1}\right)$ associated with the $4 \times 3$ SOM nodes. 


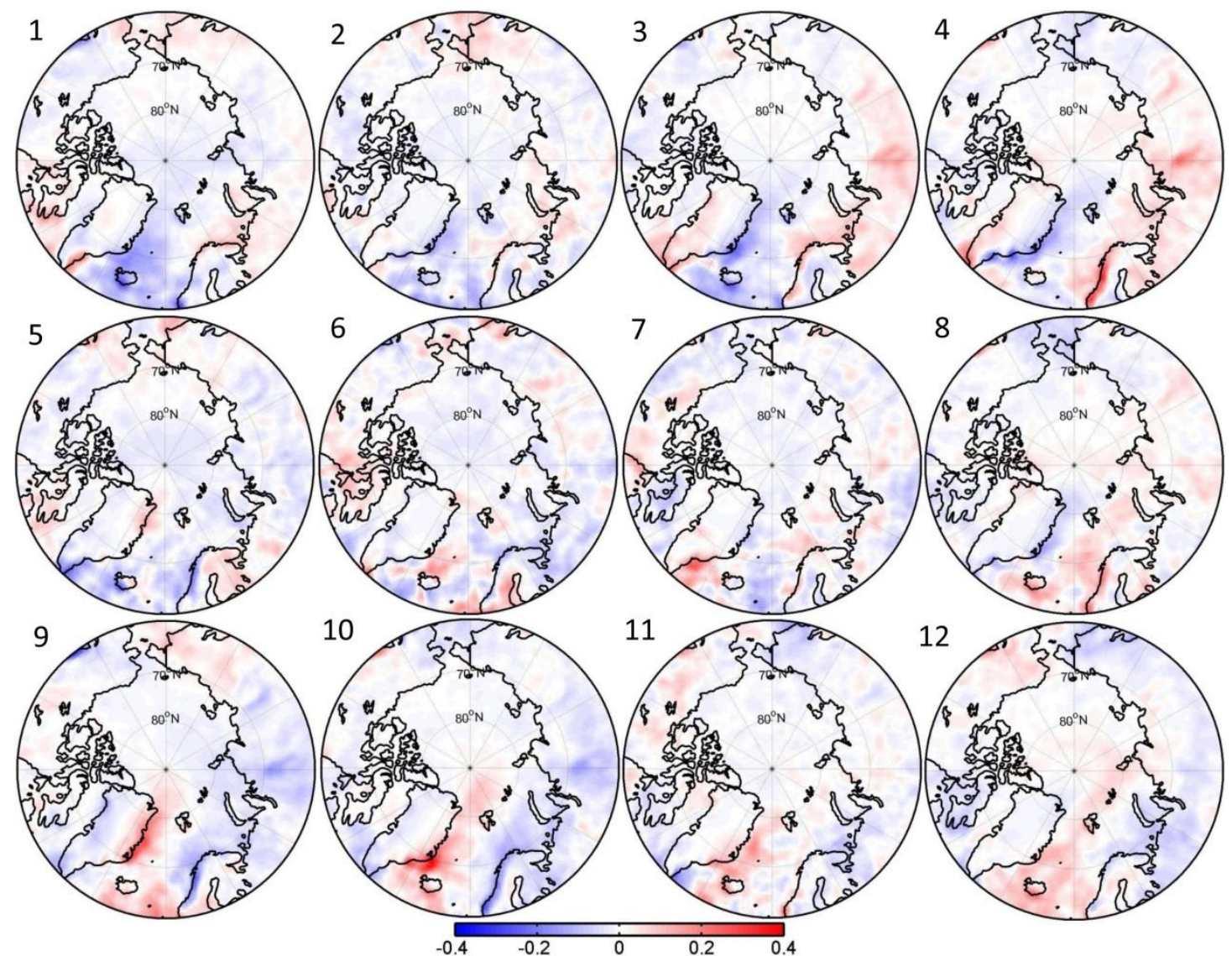

Figure 11. Autumn daily precipitation anomaly $\left(\mathrm{mm} \mathrm{day}^{-1}\right)$ associated with the $4 \times 3$ SOM nodes. 


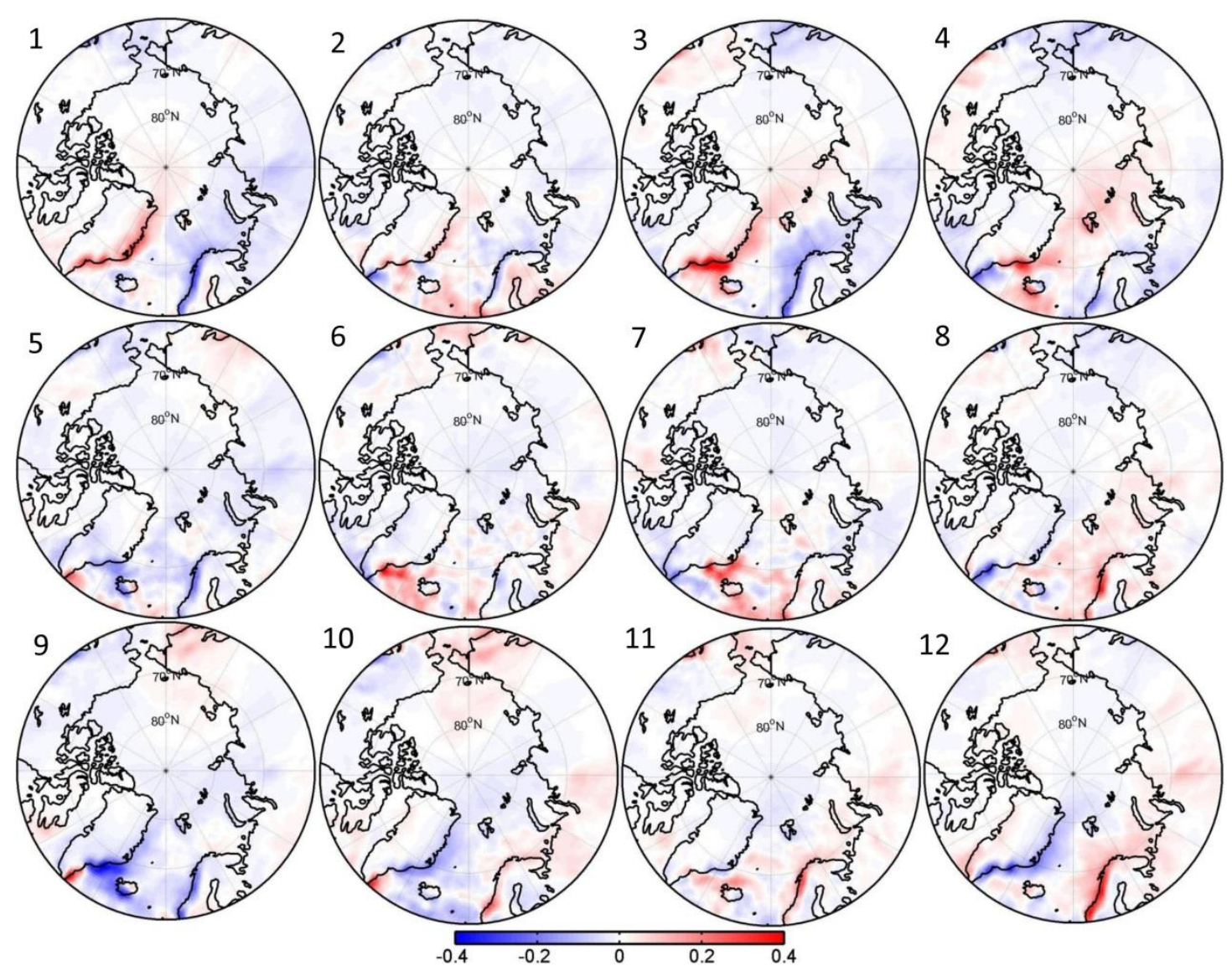

Figure 12 . Winter daily precipitation anomaly $\left(\mathrm{mm} \mathrm{day}^{-1}\right)$ associated with the $4 \times 3$ SOM nodes. 

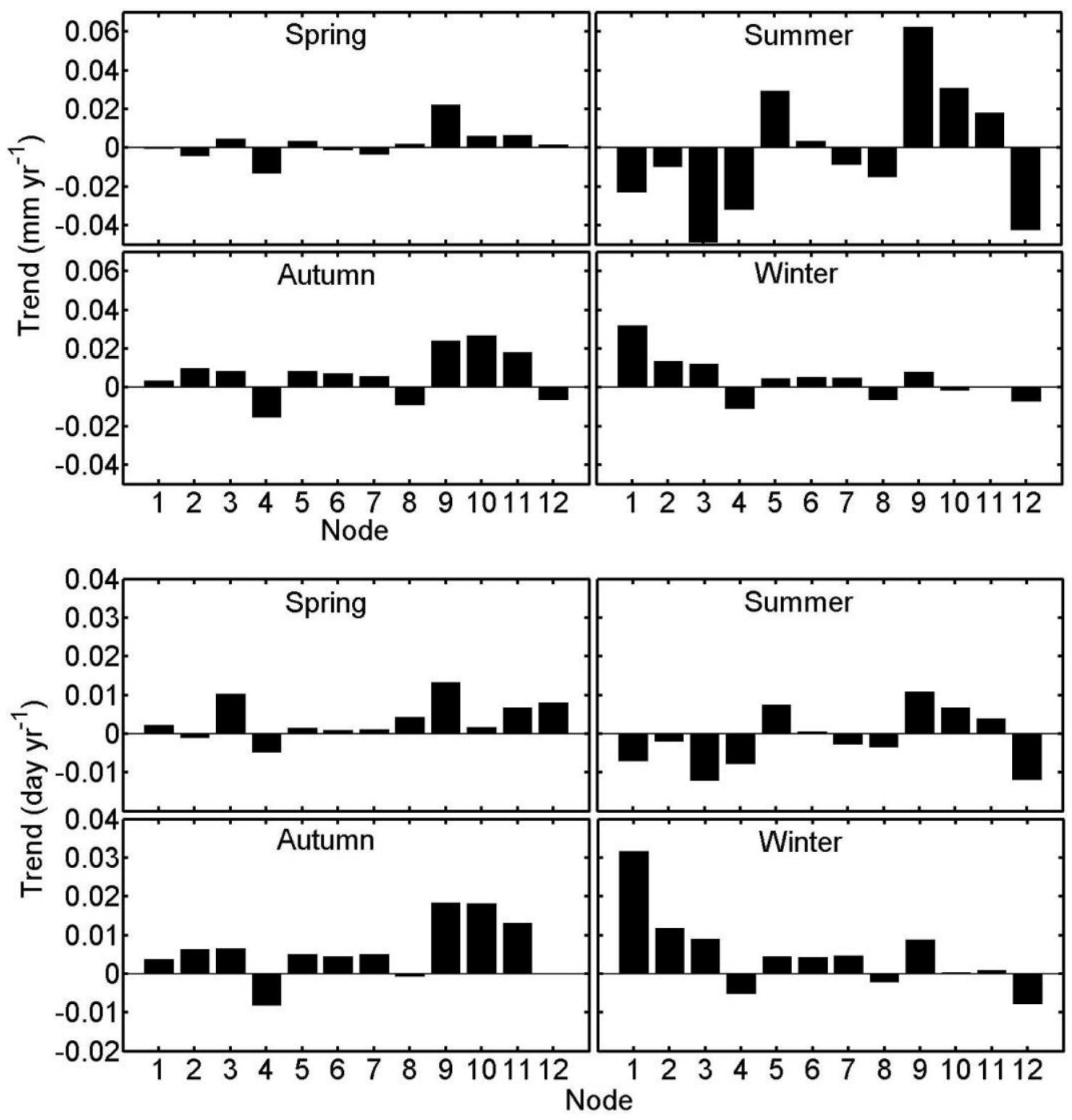

Figure 13. Trends in seasonal precipitation (upper panel) and in the number of days of extreme precipitation (lower panel) averaged over all grid points in a node where trends are significant. 


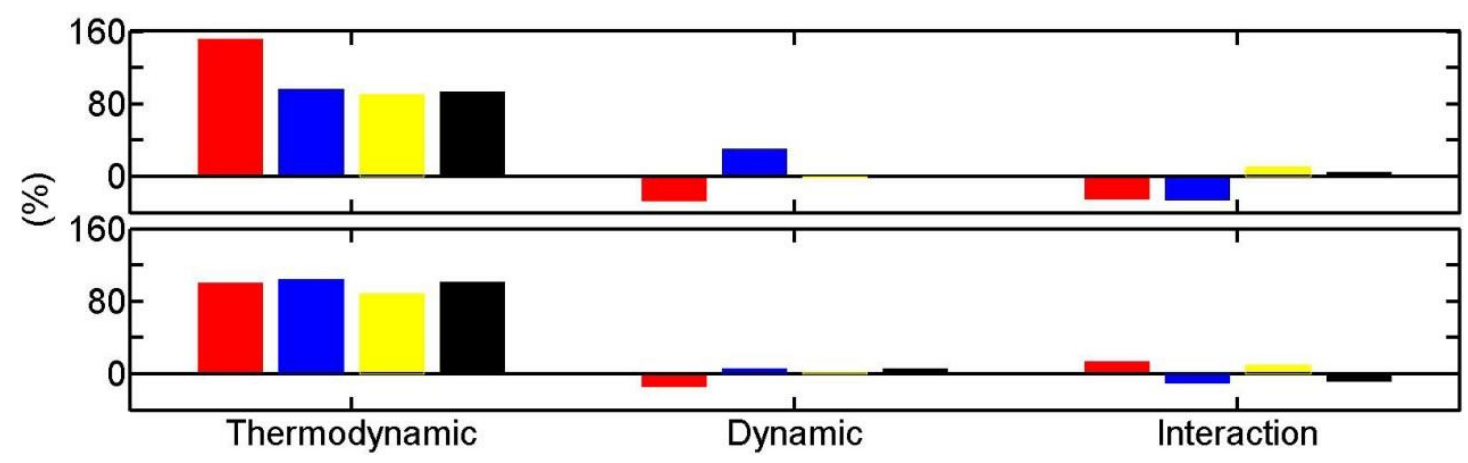

Figure 14. Percentages of trends in seasonal total precipitation amount (upper) and the number of days of extreme precipitation (lower) explained by the thermodynamic, dynamic and interaction components for spring (red), summer (blue), autumn (yellow), and winter (black). 


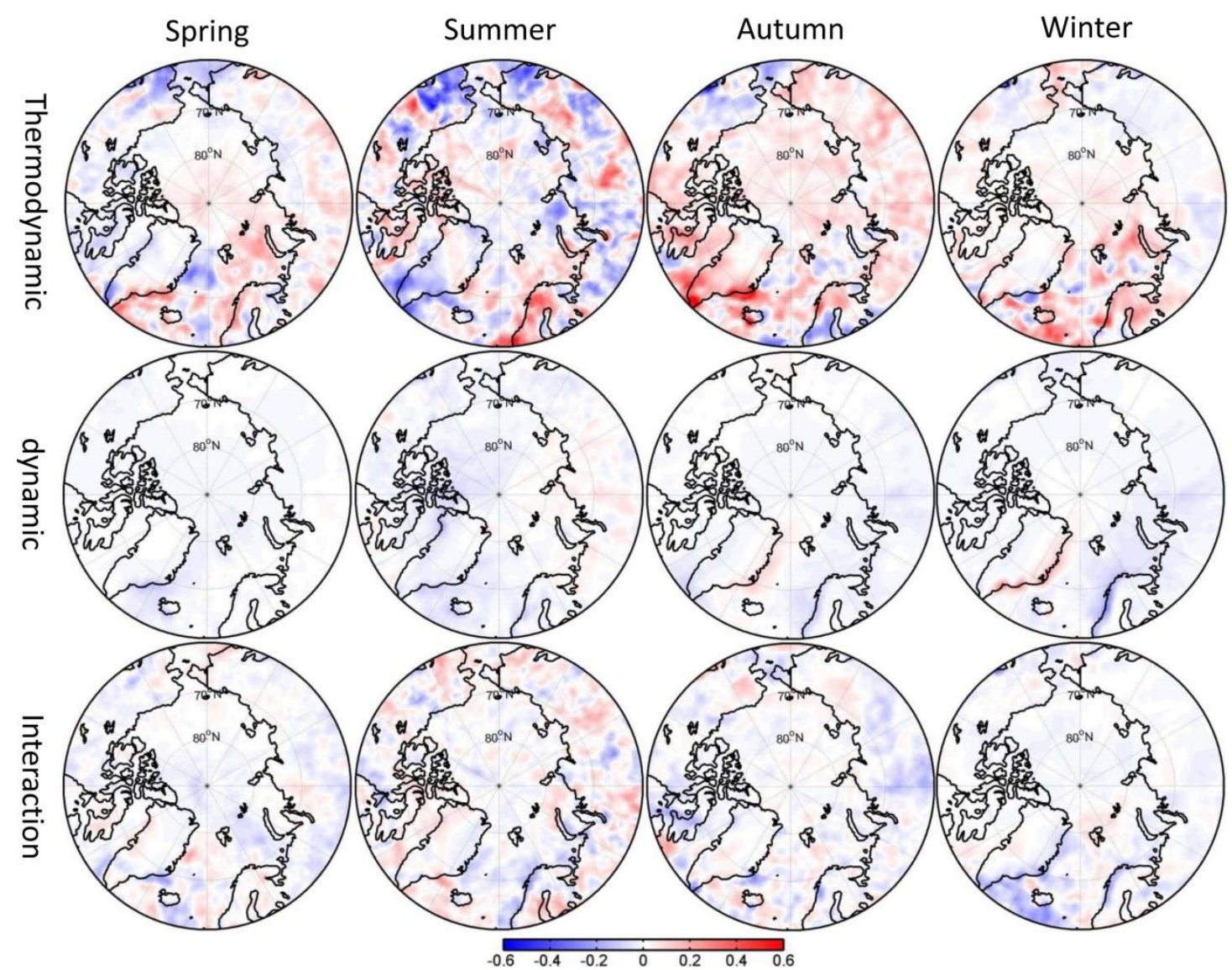

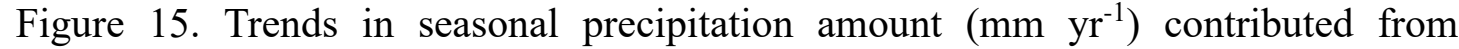
thermodynamic (top), dynamic (middle), and interaction (bottom) components for each season. 


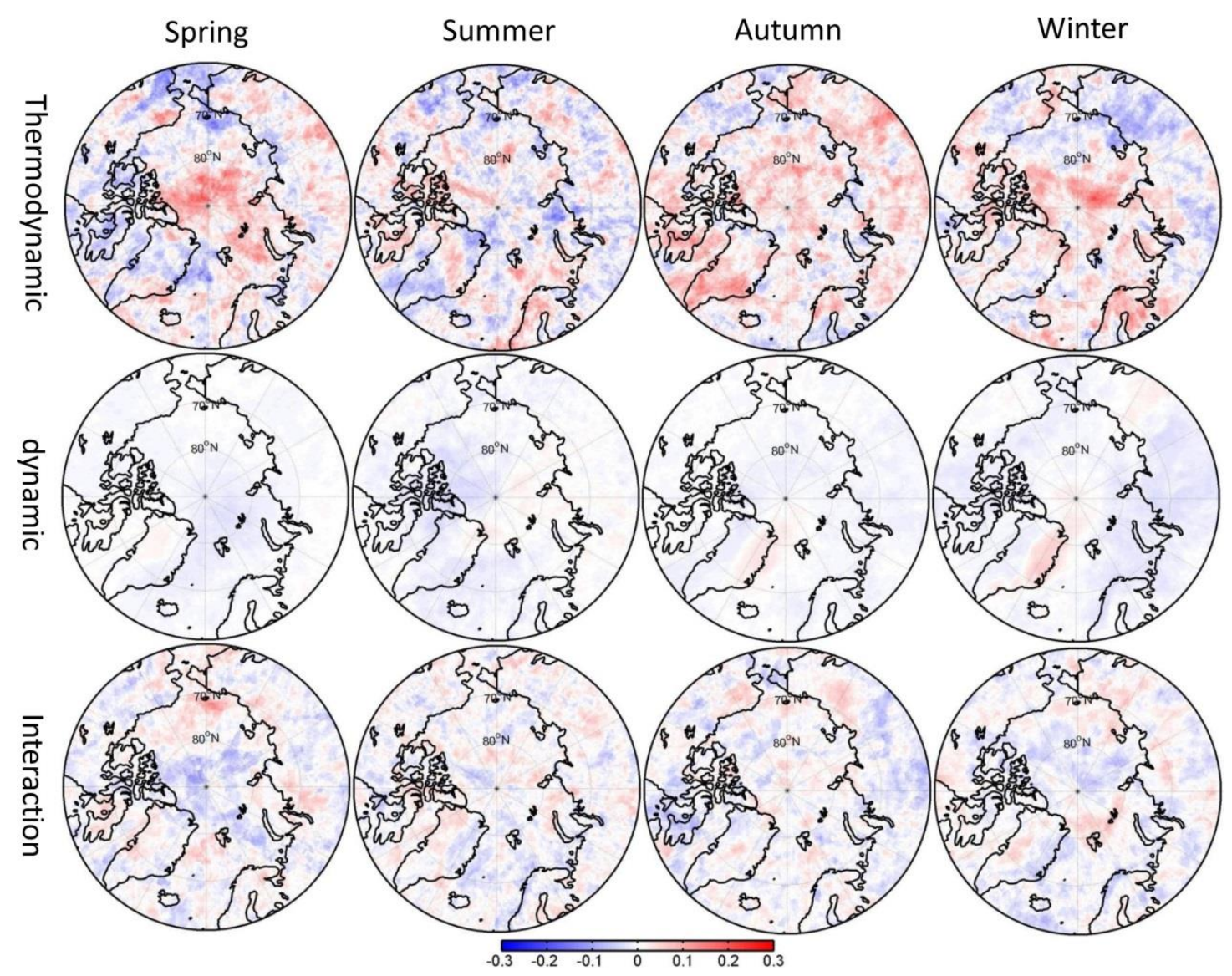

Figure 16. Same as Figure 13, but for the number of days of extreme precipitation occurrence. 

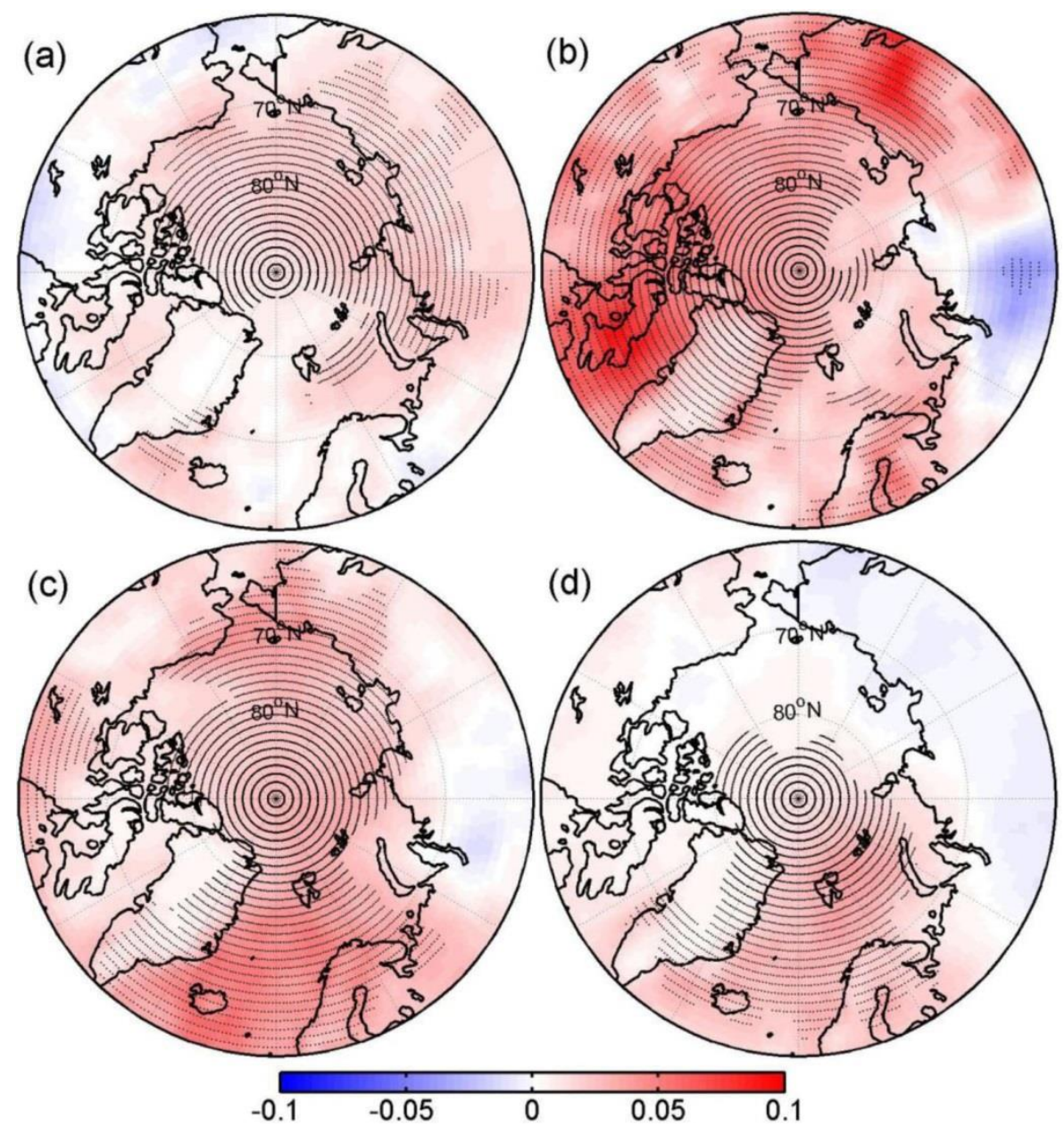

Figure 17. Trends in seasonal total column water vapor $\left(\mathrm{kg} \mathrm{m}^{-2} \mathrm{yr}^{-1}\right)$ for spring (a), summer (b), autumn (c), and winter (d) 
Figures

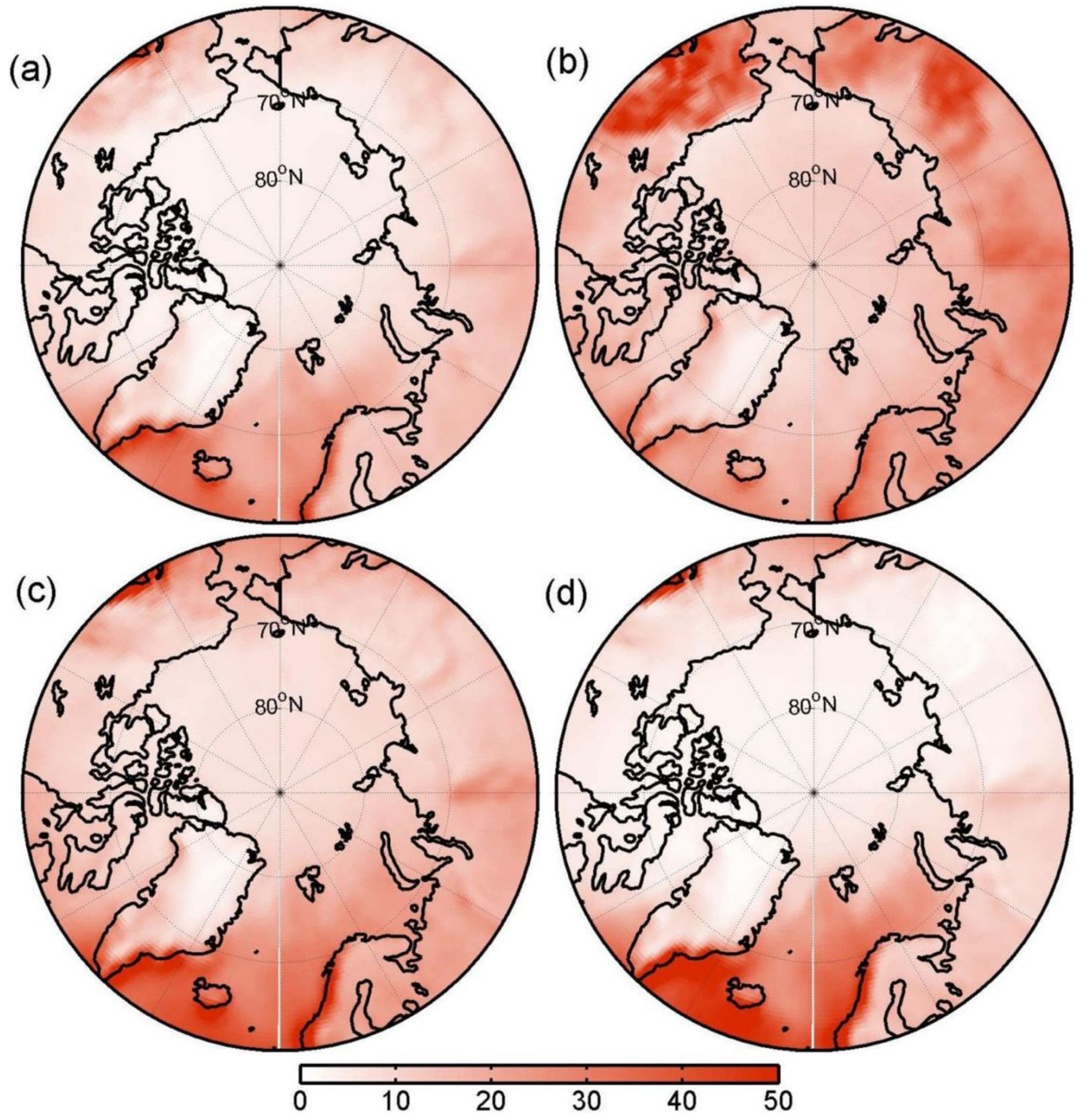

Figure 1

Climatology of seasonal total precipitation (units: $\mathrm{mm}$ ) for spring (March-may) (a), summer (JuneAugust) (b), autumn (September-November) (c), and winter (December-February) (d) for the 1979-2016 period. Note: The designations employed and the presentation of the material on this map do not imply 
the expression of any opinion whatsoever on the part of Research Square concerning the legal status of any country, territory, city or area or of its authorities, or concerning the delimitation of its frontiers or boundaries. This map has been provided by the authors.

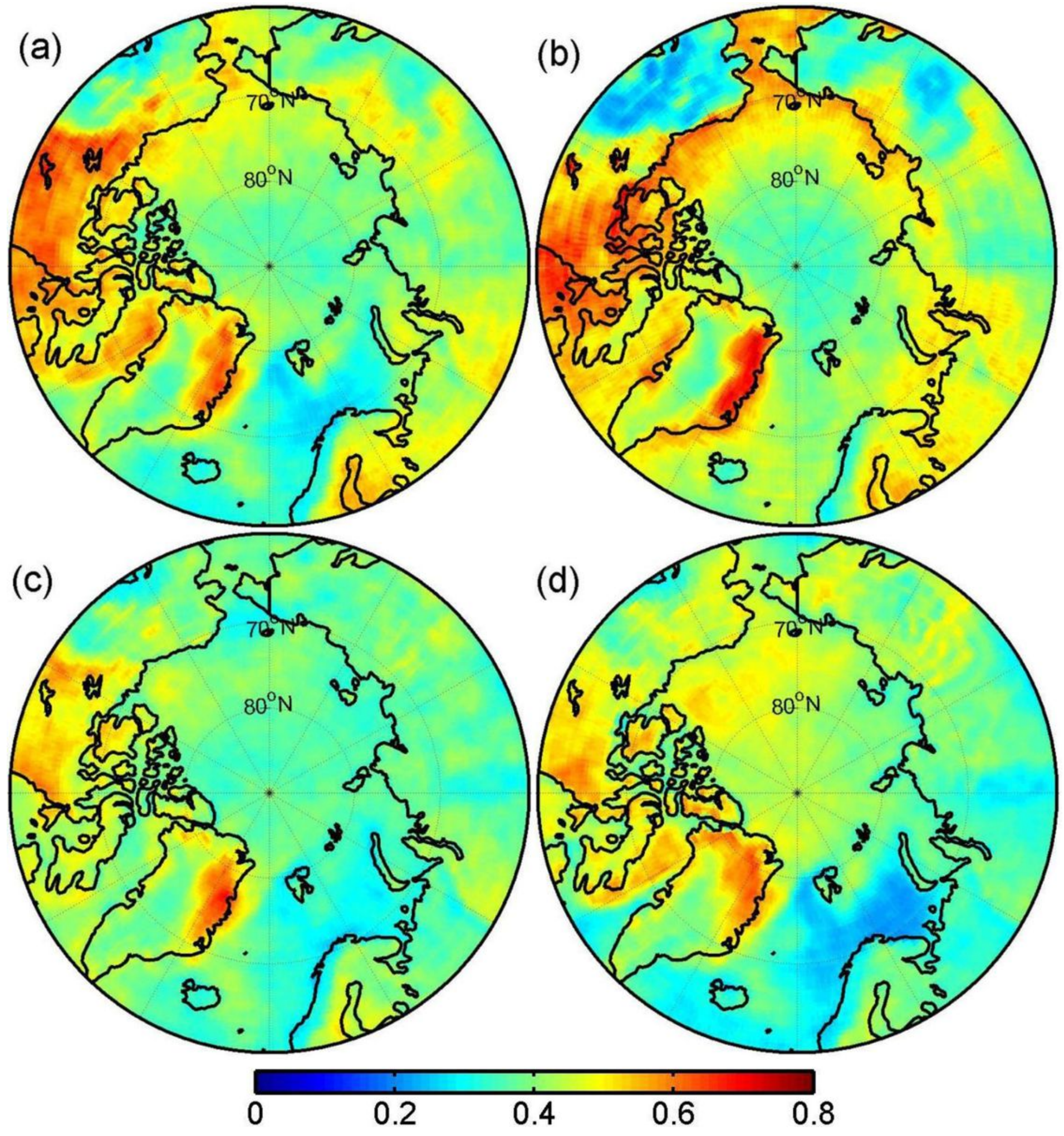

Figure 2

Ratios of the seasonal extreme precipitation amount to the seasonal total precipitation amount for spring (a), summer (b), autumn (c), and winter (d) for the 1979-2016 period. Note: The designations employed 
and the presentation of the material on this map do not imply the expression of any opinion whatsoever on the part of Research Square concerning the legal status of any country, territory, city or area or of its authorities, or concerning the delimitation of its frontiers or boundaries. This map has been provided by the authors.

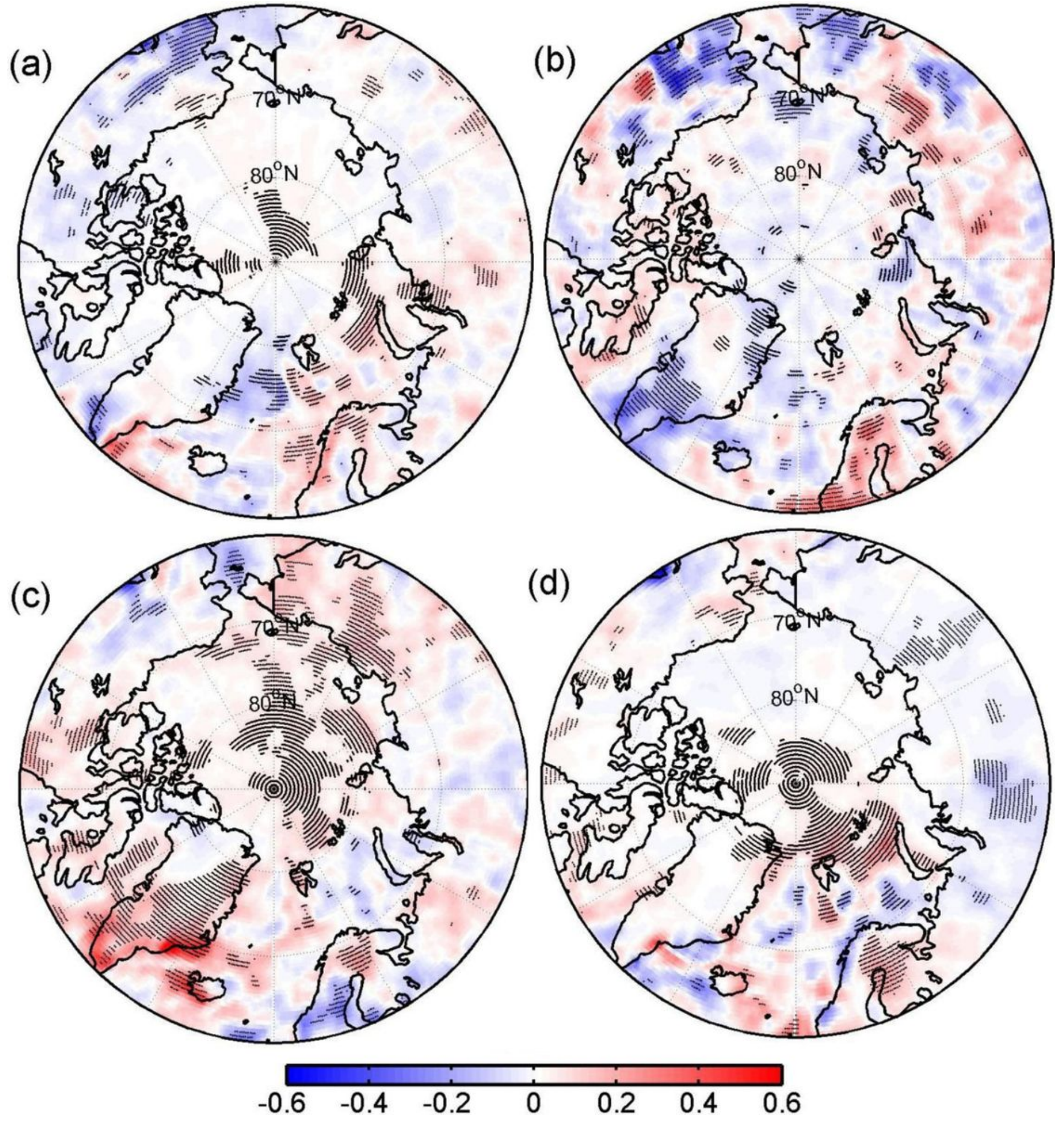

Figure 3 
Trends in seasonal total precipitation (units: mm yr-1) for spring (a), summer (b), autumn (c), and winter (d) for the 1979-2016 period. Dotted regions indicate the above 95\% confidence level. Note: The designations employed and the presentation of the material on this map do not imply the expression of any opinion whatsoever on the part of Research Square concerning the legal status of any country, territory, city or area or of its authorities, or concerning the delimitation of its frontiers or boundaries. This map has been provided by the authors.

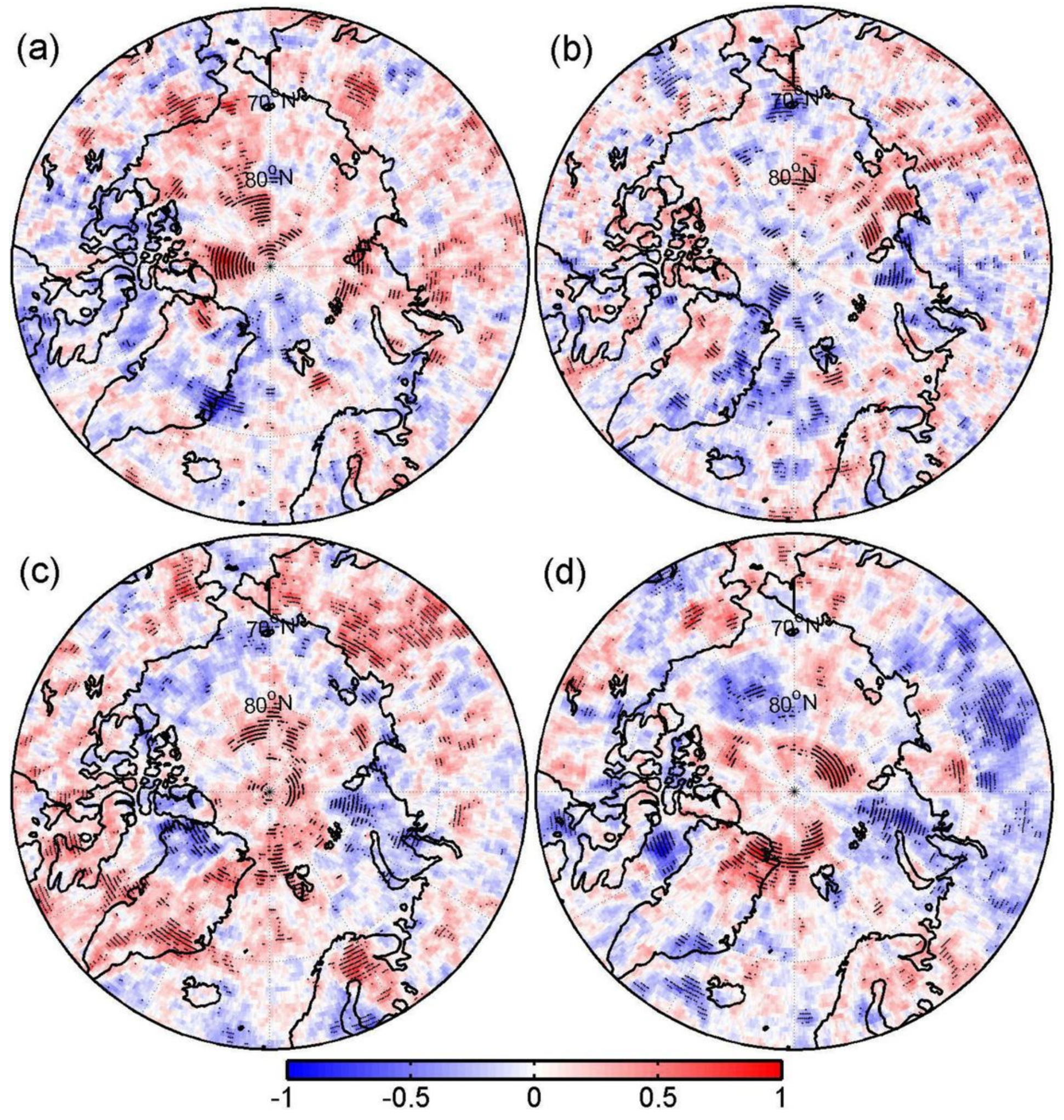

Figure 4 
The same as Figure 3, but for ratios of the seasonal extreme precipitation amount to the seasonal total precipitation amount (units: yr-1). Note: The designations employed and the presentation of the material on this map do not imply the expression of any opinion whatsoever on the part of Research Square concerning the legal status of any country, territory, city or area or of its authorities, or concerning the delimitation of its frontiers or boundaries. This map has been provided by the authors.

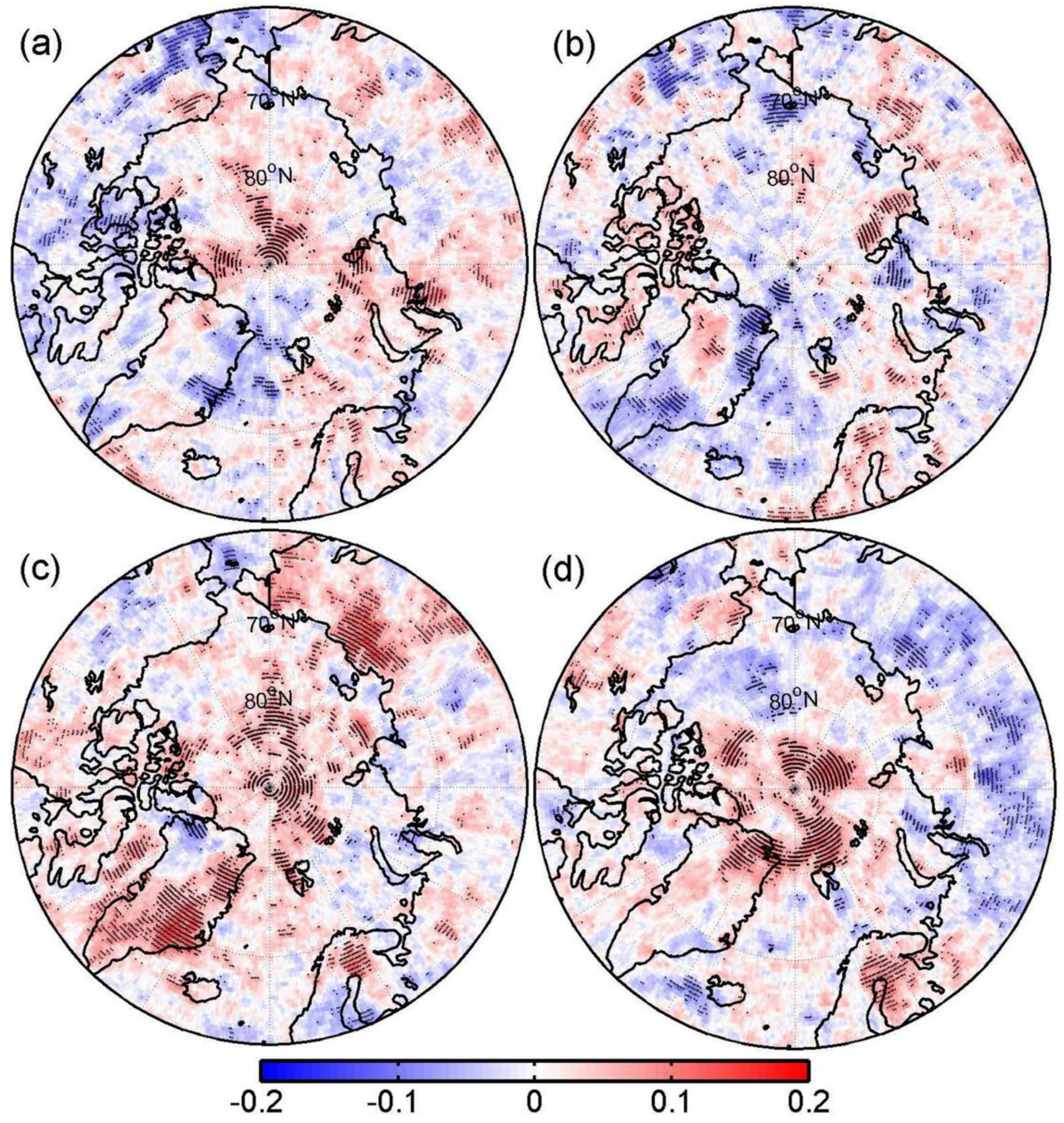

Figure 5 
The same as Figure 3, but for the number of days (units: day yr-1) of the seasonal extreme precipitation occurrences. Note: The designations employed and the presentation of the material on this map do not imply the expression of any opinion whatsoever on the part of Research Square concerning the legal status of any country, territory, city or area or of its authorities, or concerning the delimitation of its frontiers or boundaries. This map has been provided by the authors.

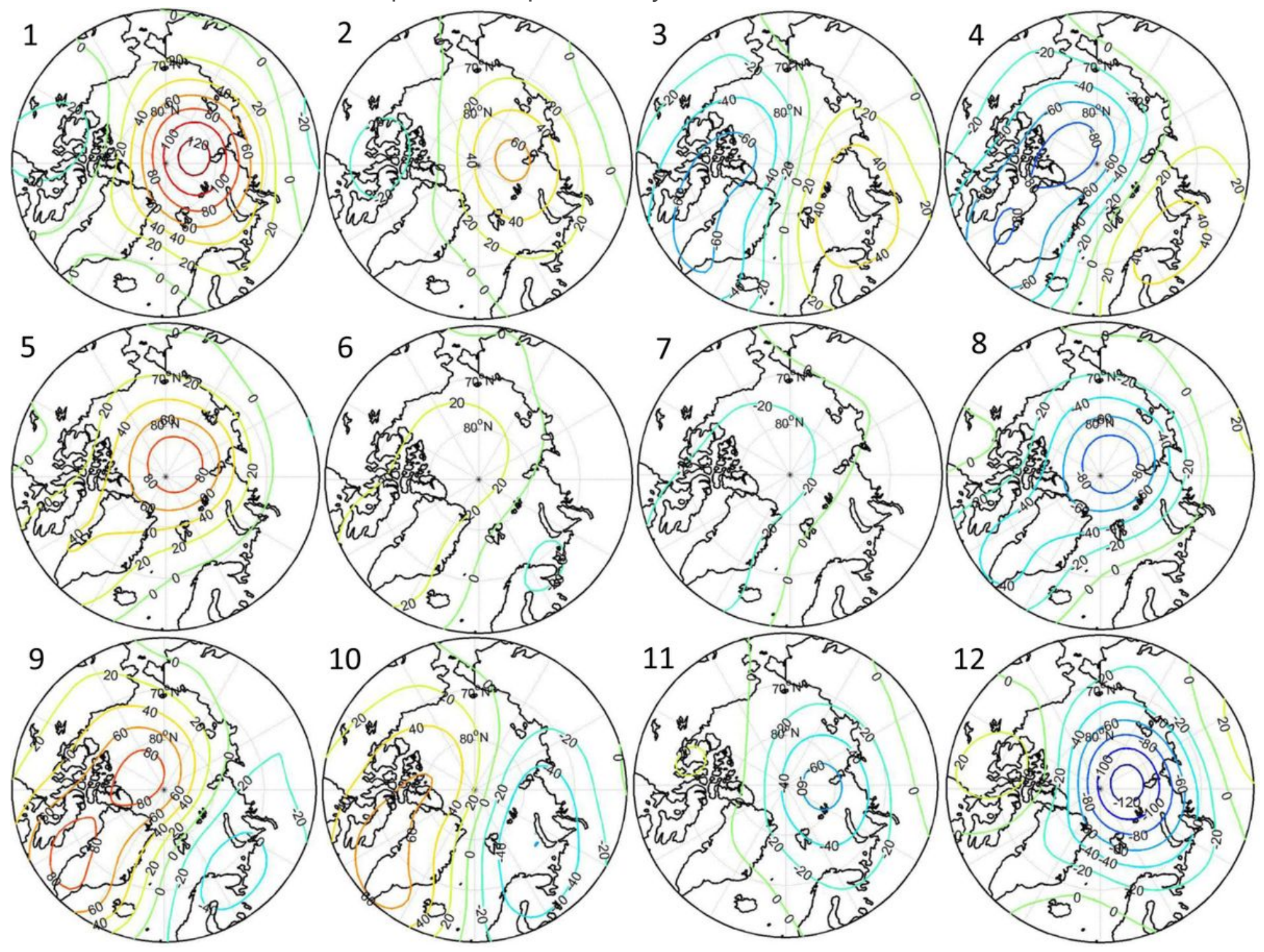

Figure 6

The spring $500-\mathrm{hPa}$ geopotential height (gpm) anomaly patterns on the $4 \times 3 \mathrm{SOM}$ nodes. Note: The designations employed and the presentation of the material on this map do not imply the expression of any opinion whatsoever on the part of Research Square concerning the legal status of any country, territory, city or area or of its authorities, or concerning the delimitation of its frontiers or boundaries. This map has been provided by the authors. 


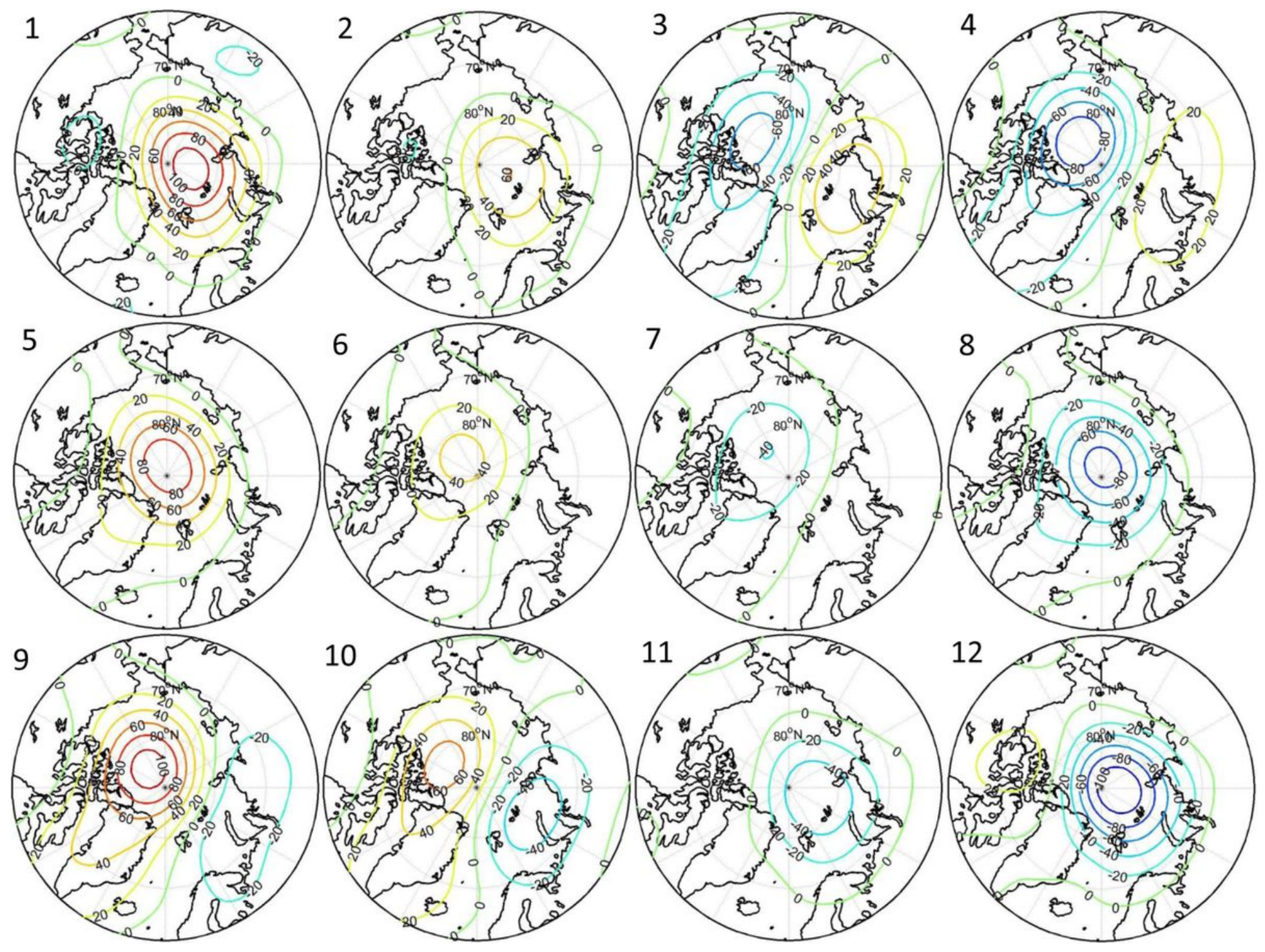

Figure 7

The summer $500-\mathrm{hPa}$ geopotential height (gpm) anomaly patterns on the $4 \times 3 \mathrm{SOM}$ nodes. Note: The designations employed and the presentation of the material on this map do not imply the expression of any opinion whatsoever on the part of Research Square concerning the legal status of any country, territory, city or area or of its authorities, or concerning the delimitation of its frontiers or boundaries. This map has been provided by the authors. 


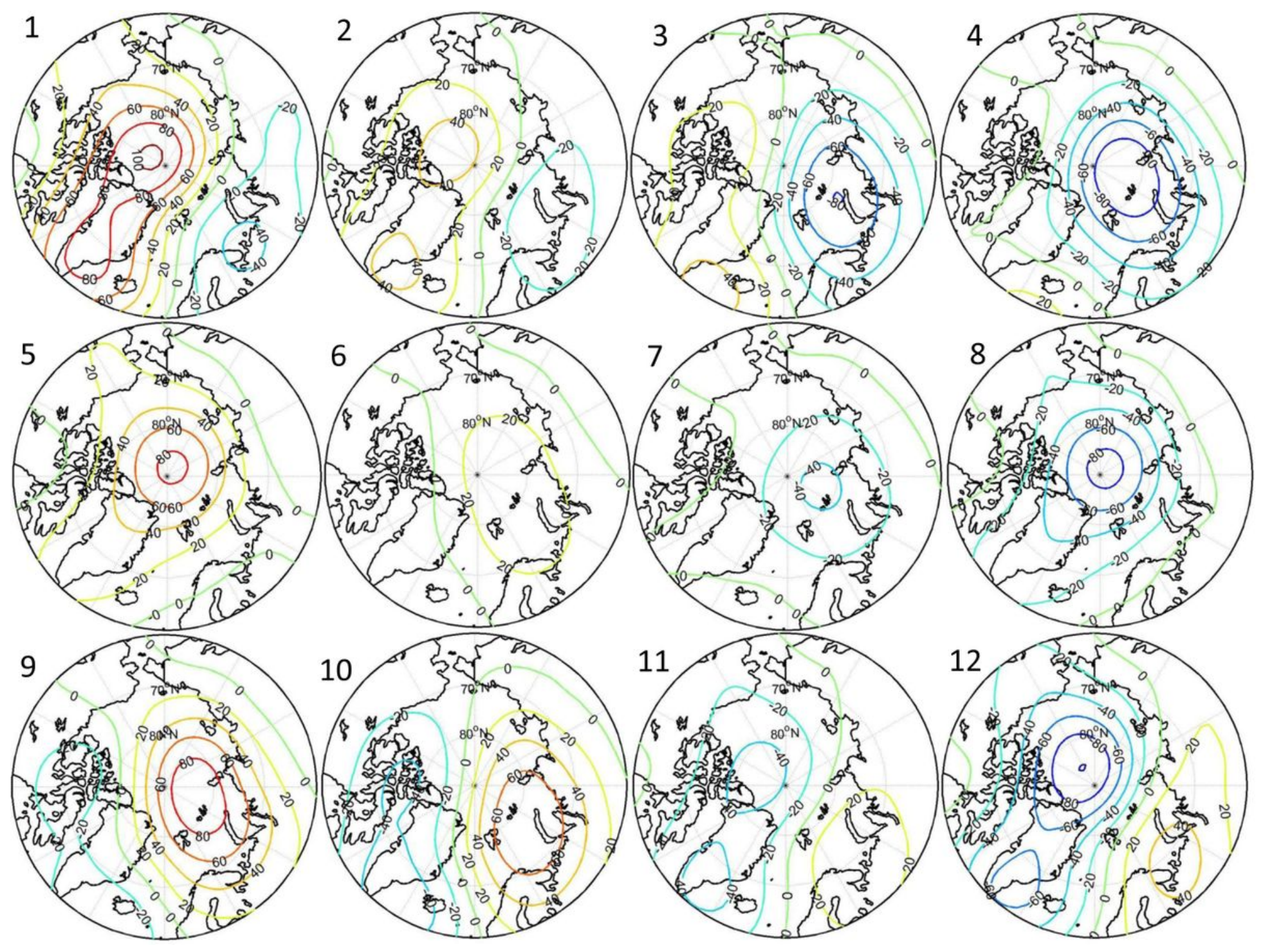

Figure 8

The autumn $500-\mathrm{hPa}$ geopotential height (gpm) anomaly patterns on the $4 \times 3 \mathrm{SOM}$ nodes. Note: The designations employed and the presentation of the material on this map do not imply the expression of any opinion whatsoever on the part of Research Square concerning the legal status of any country, territory, city or area or of its authorities, or concerning the delimitation of its frontiers or boundaries. This map has been provided by the authors. 


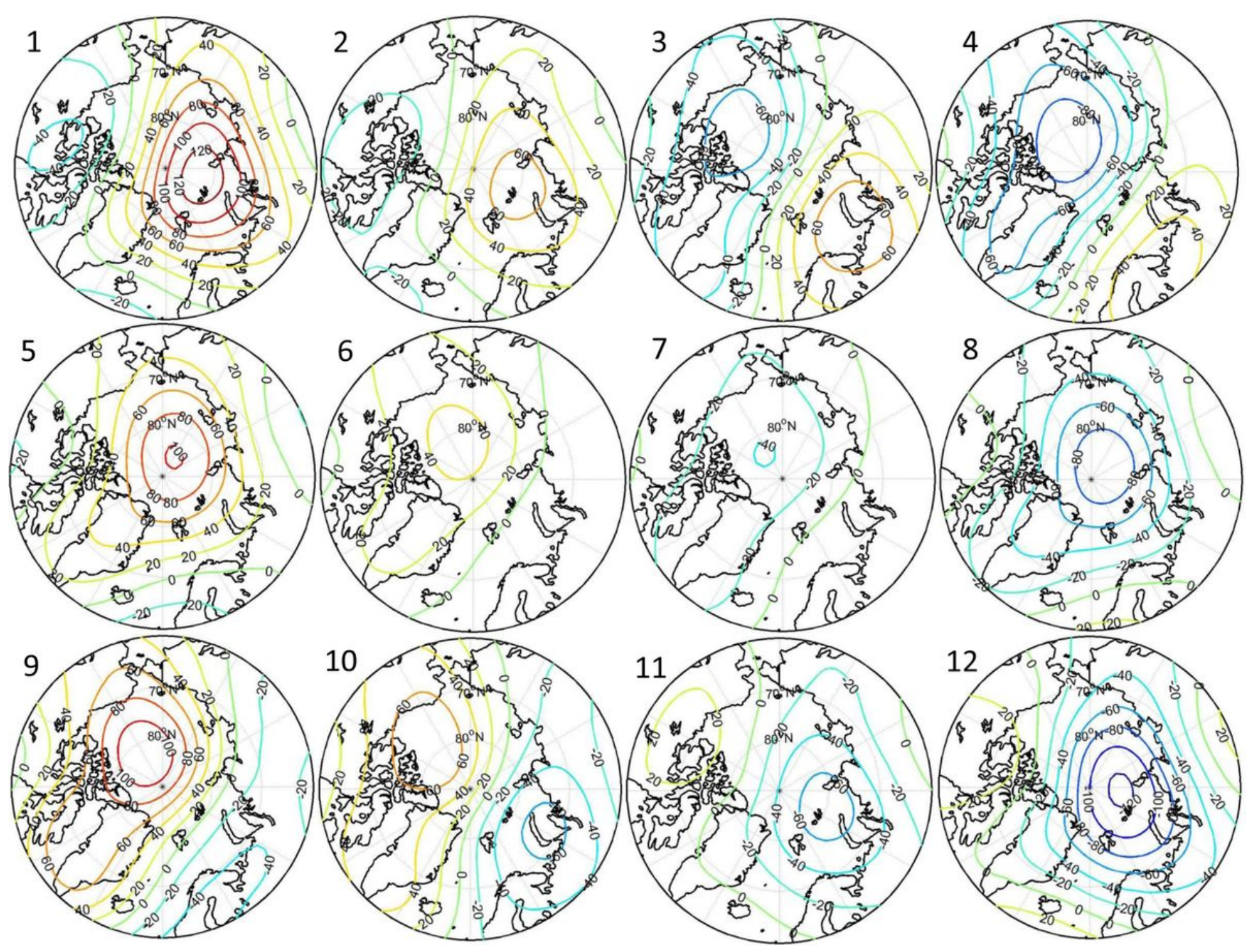

Figure 9

The winter $500-\mathrm{hPa}$ geopotential height (gpm) anomaly patterns on the $4 \times 3$ SOM nodes. Note: The designations employed and the presentation of the material on this map do not imply the expression of any opinion whatsoever on the part of Research Square concerning the legal status of any country, territory, city or area or of its authorities, or concerning the delimitation of its frontiers or boundaries. This map has been provided by the authors. 


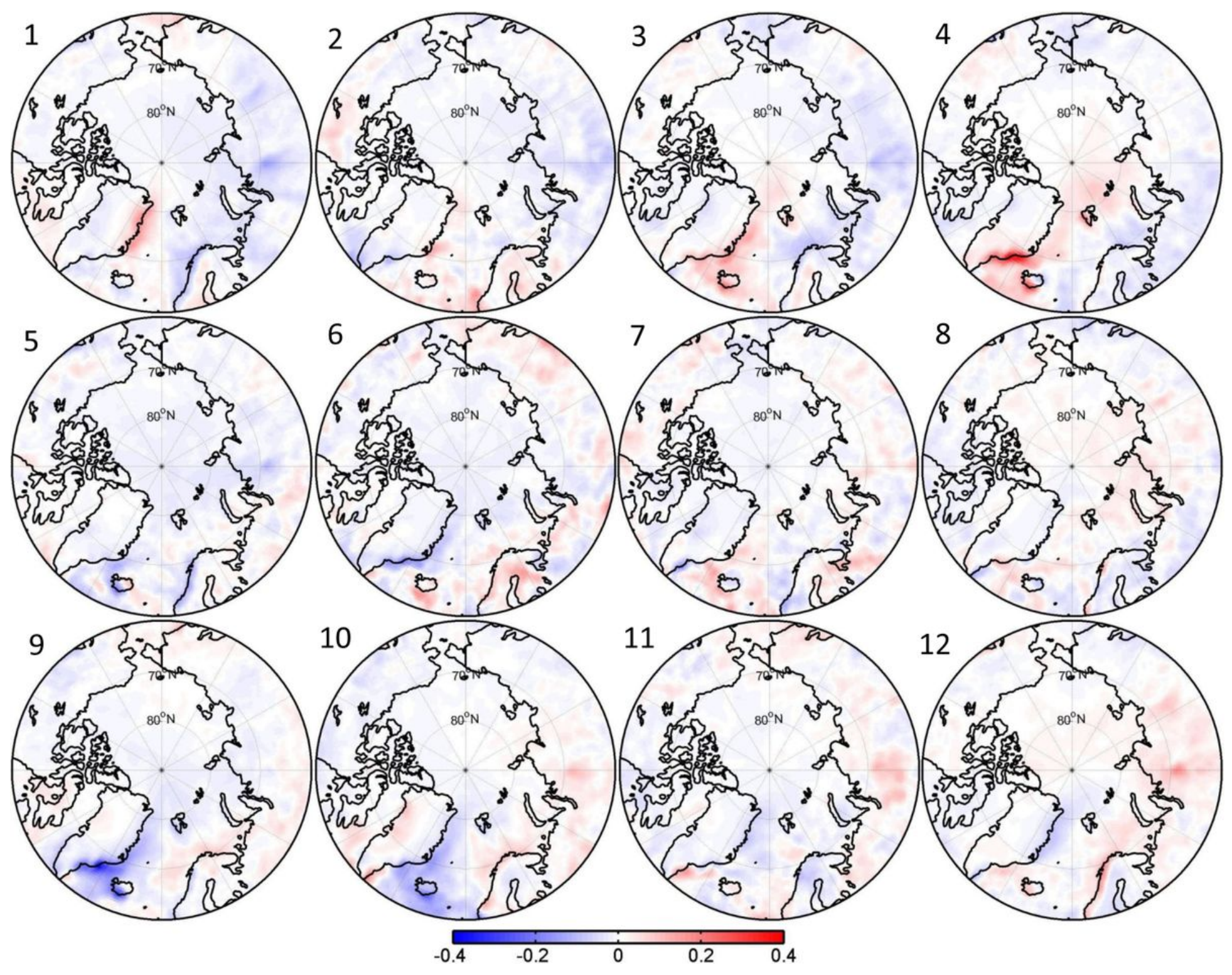

Figure 10

Spring daily precipitation anomaly ( $\mathrm{mm}$ day -1$)$ associated with the $4 \times 3$ SOM nodes. Note: The designations employed and the presentation of the material on this map do not imply the expression of any opinion whatsoever on the part of Research Square concerning the legal status of any country, territory, city or area or of its authorities, or concerning the delimitation of its frontiers or boundaries. This map has been provided by the authors. 


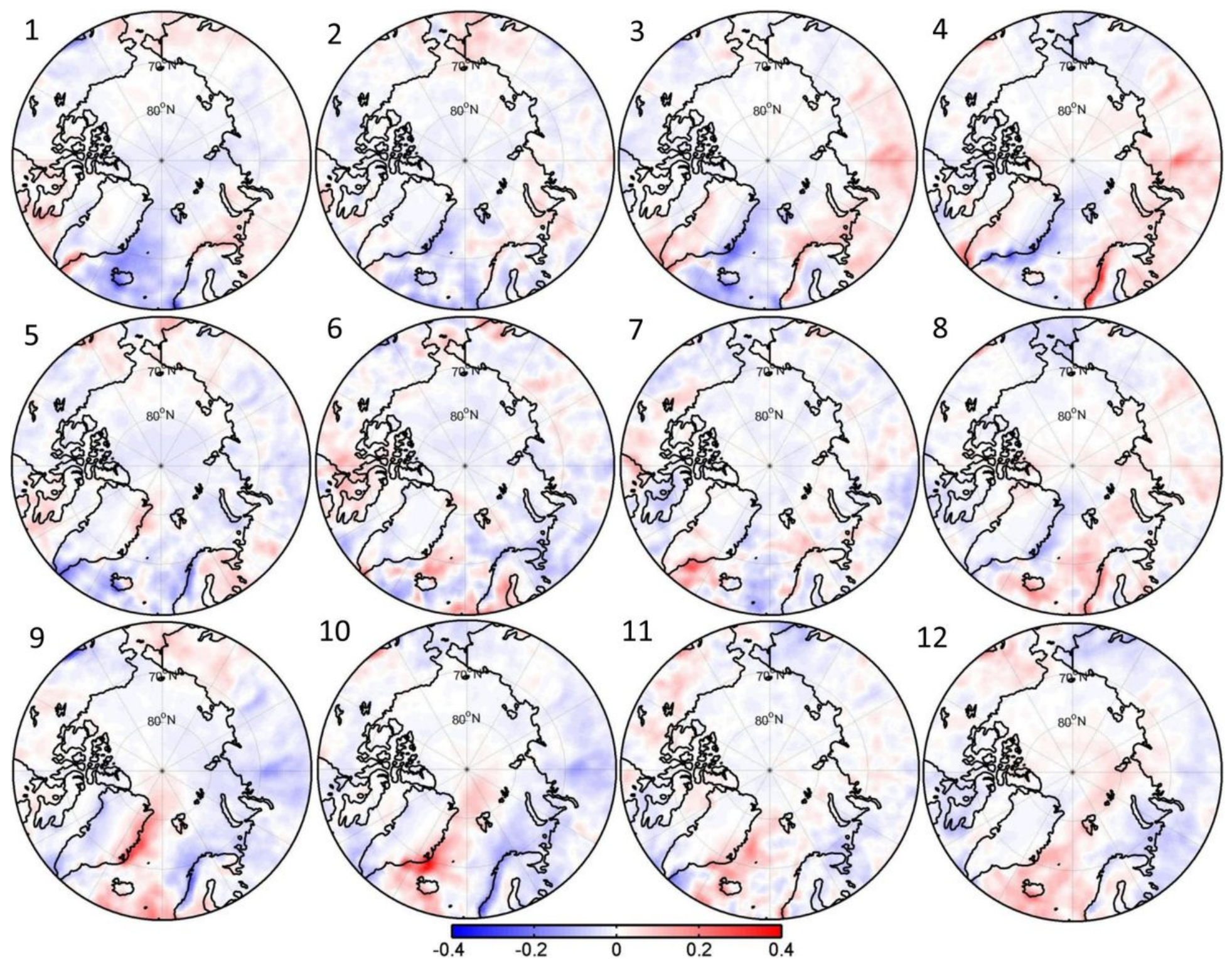

Figure 11

Autumn daily precipitation anomaly (mm day- 1 ) associated with the $4 \times 3$ SOM nodes. Note: The designations employed and the presentation of the material on this map do not imply the expression of any opinion whatsoever on the part of Research Square concerning the legal status of any country, territory, city or area or of its authorities, or concerning the delimitation of its frontiers or boundaries. This map has been provided by the authors. 


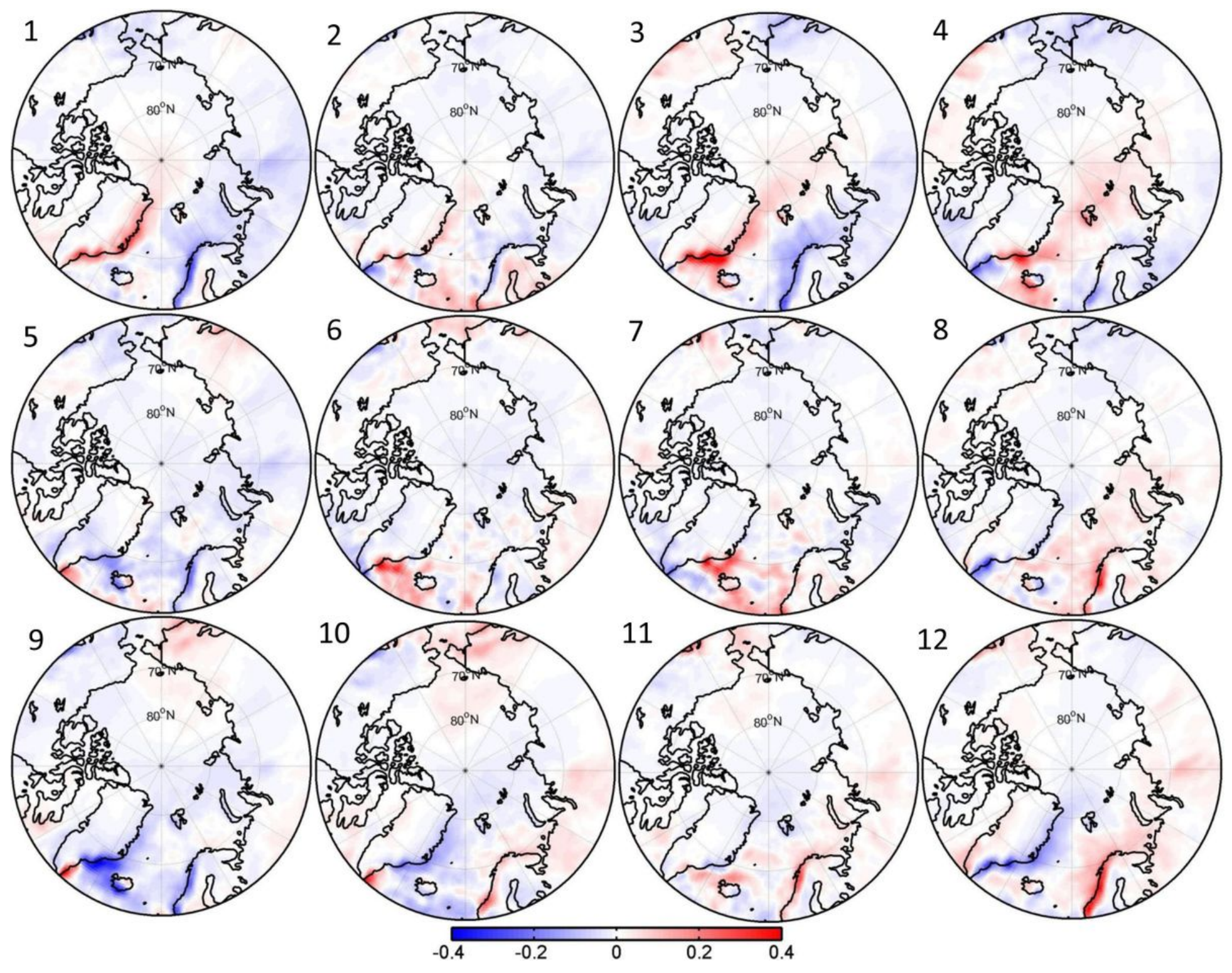

Figure 12

Winter daily precipitation anomaly ( $\mathrm{mm}$ day -1$)$ associated with the $4 \times 3$ SOM nodes. Note: The designations employed and the presentation of the material on this map do not imply the expression of any opinion whatsoever on the part of Research Square concerning the legal status of any country, territory, city or area or of its authorities, or concerning the delimitation of its frontiers or boundaries. This map has been provided by the authors. 


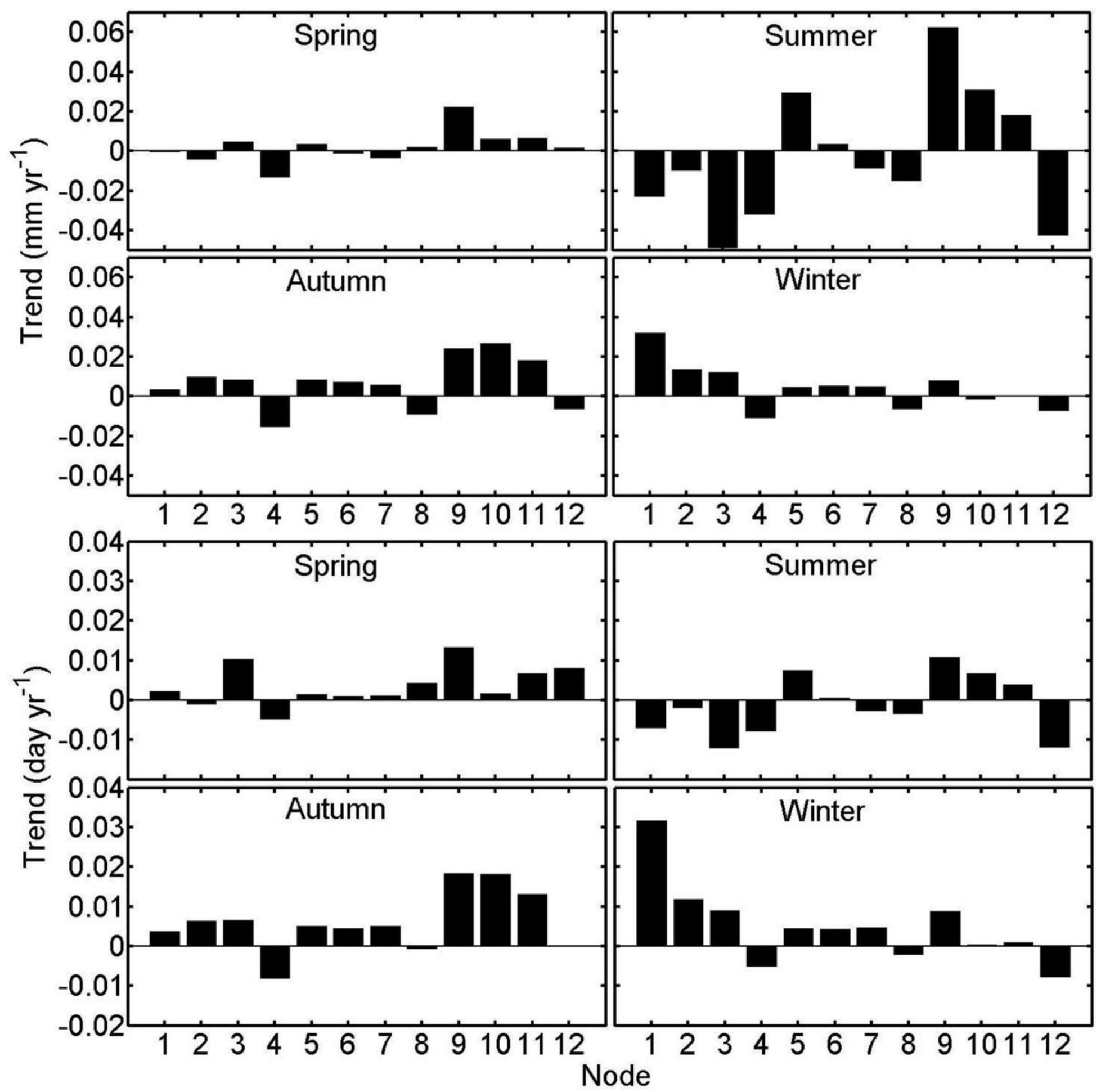

Figure 13

Trends in seasonal precipitation (upper panel) and in the number of days of extreme precipitation (lower panel) averaged over all grid points in a node where trends are significant. 


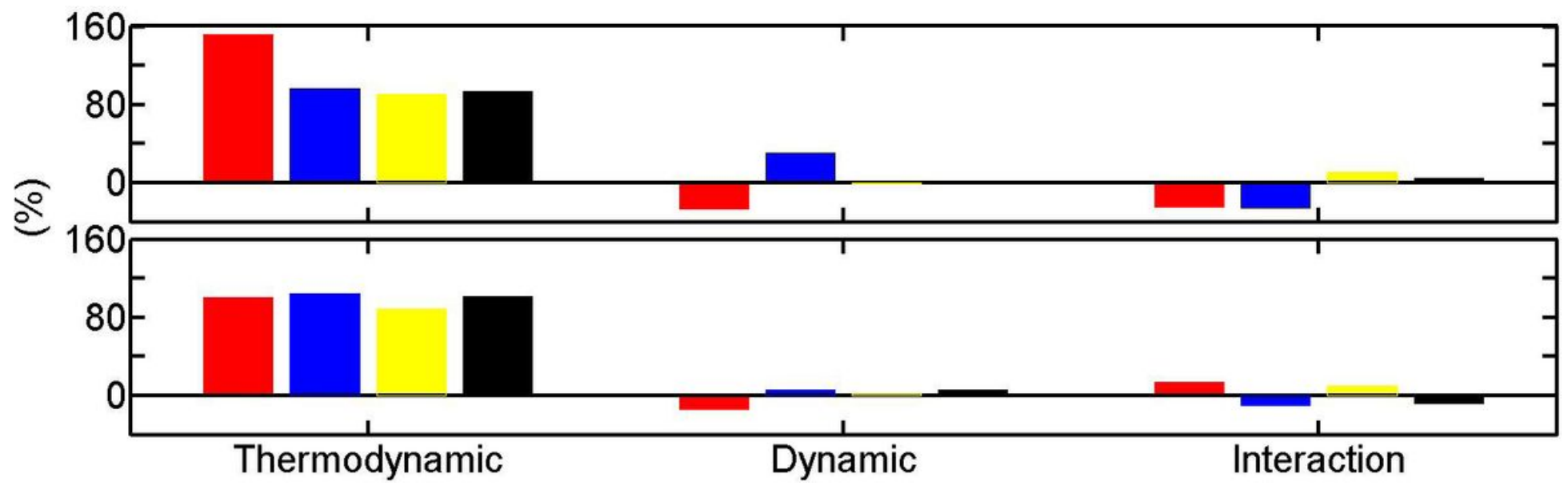

Figure 14

Percentages of trends in seasonal total precipitation amount (upper) and the number of days of extreme precipitation (lower) explained by the thermodynamic, dynamic and interaction components for spring (red), summer (blue), autumn (yellow), and winter (black).

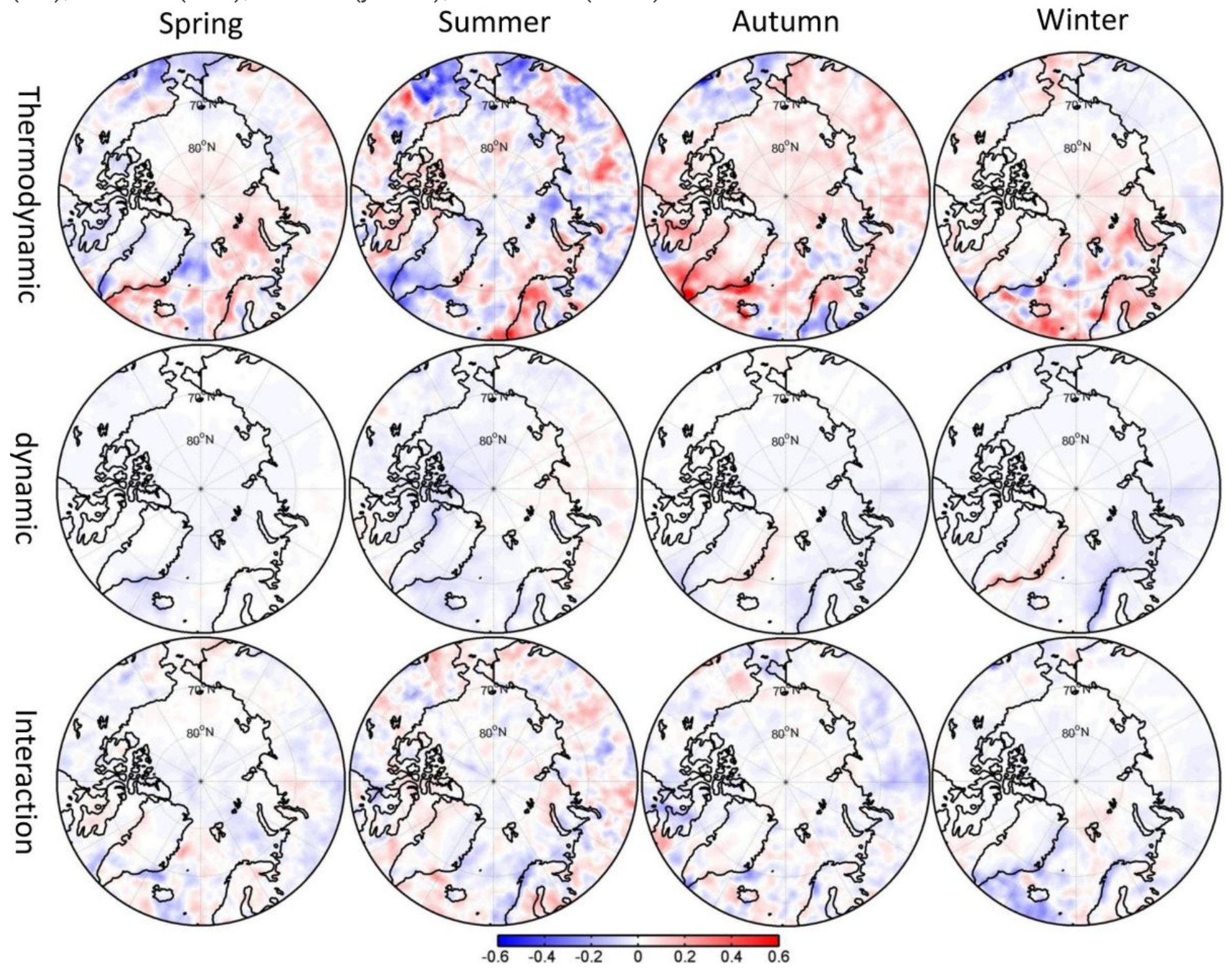


Figure 15

Trends in seasonal precipitation amount (mm yr-1) contributed from thermodynamic (top), dynamic (middle), and interaction (bottom) components for each season. Note: The designations employed and the presentation of the material on this map do not imply the expression of any opinion whatsoever on the part of Research Square concerning the legal status of any country, territory, city or area or of its authorities, or concerning the delimitation of its frontiers or boundaries. This map has been provided by the authors.

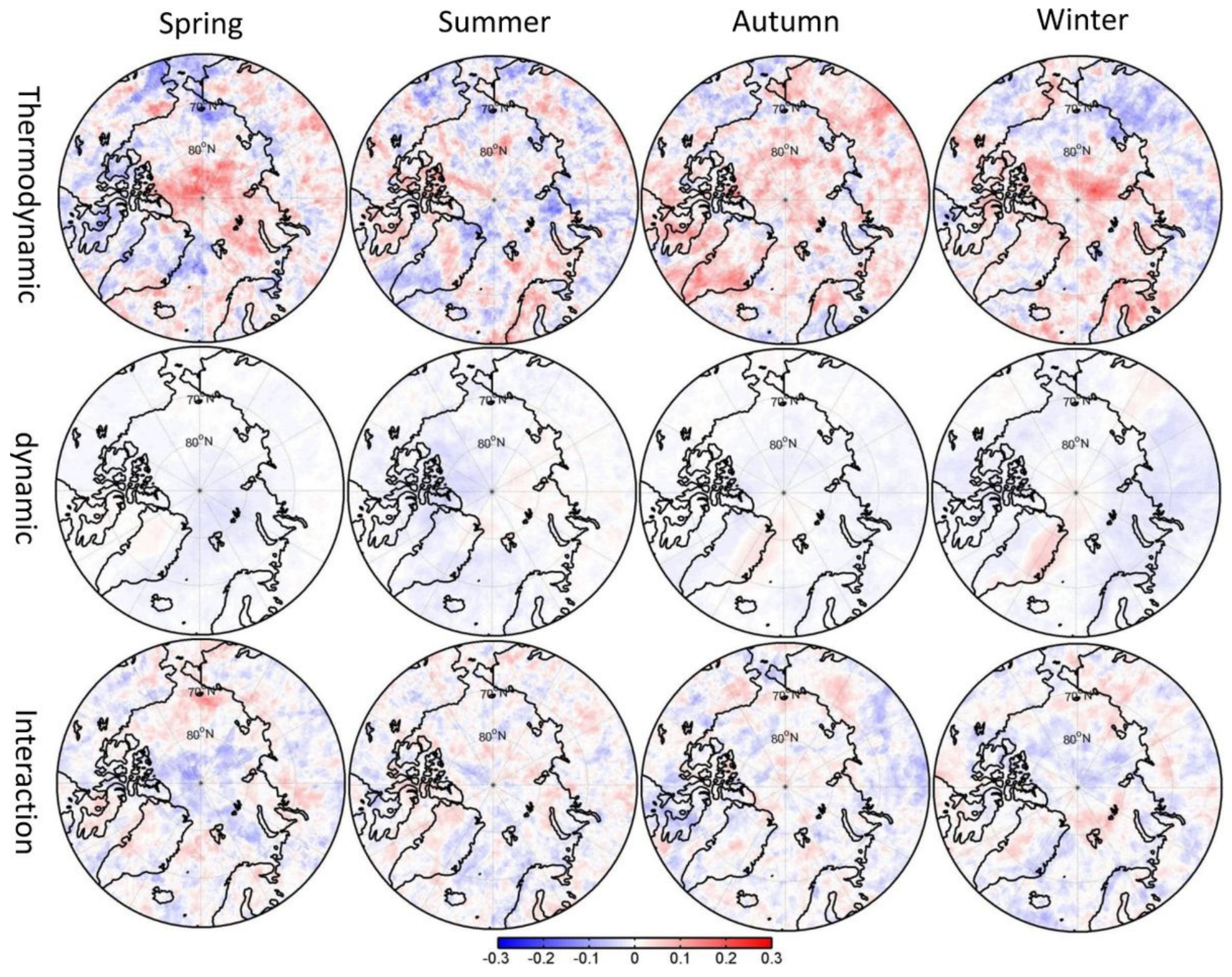

Figure 16

Same as Figure 13, but for the number of days of extreme precipitation occurrence. Note: The designations employed and the presentation of the material on this map do not imply the expression of any opinion whatsoever on the part of Research Square concerning the legal status of any country, territory, city or area or of its authorities, or concerning the delimitation of its frontiers or boundaries. This map has been provided by the authors. 


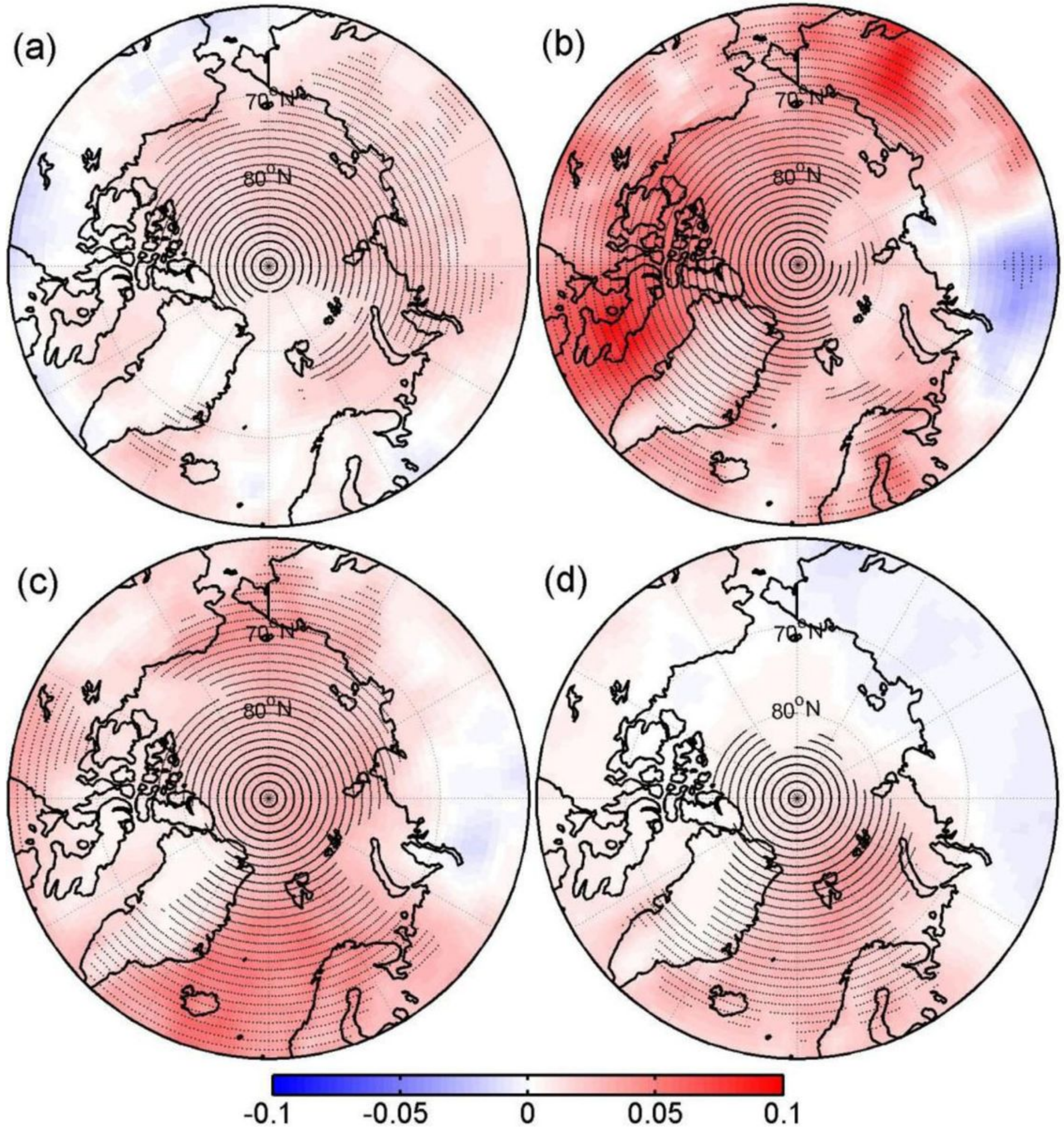

Figure 17

Trends in seasonal total column water vapor (kg m-2 yr-1) for spring (a), summer (b), autumn (c), and winter (d). Note: The designations employed and the presentation of the material on this map do not imply the expression of any opinion whatsoever on the part of Research Square concerning the legal status of any country, territory, city or area or of its authorities, or concerning the delimitation of its frontiers or boundaries. This map has been provided by the authors. 